\title{
STARTUP INSTABILITY IN NATURAL CIRCULATION DRIVEN NUCLEAR REACTORS
}

\author{
Shanbin Shi ${ }^{\mathrm{a}}$, Takashi Hibiki ${ }^{\mathrm{b}}$, Mamoru Ishii ${ }^{\mathrm{b}}$ \\ ${ }^{\mathrm{a}}$ Department of Mechanical and Aerospace Engineering, The Ohio State University \\ 281 West Lane Avenue, Columbus, OH 43210 \\ ${ }^{\mathrm{b}} \mathrm{School}$ of Nuclear Engineering, Purdue University \\ 400 Central Drive, West Lafayette, IN 47907
}

\begin{abstract}
Natural circulation driven nuclear reactors are prone to flow instability during the startup transients. This paper intends to provide the state-of-the-art reviews on the theoretical analysis and experimental studies on flow instability in three types of natural circulation driven reactors, ranging from conventional nuclear reactors to small modular reactors. Brief overviews of three categories of startup flow instability, i.e., density wave oscillations, flashing instability, and Geysering instability, are provided. A critical review is conducted for the scaling analysis and design of small scaled test facility. The review of obtaining quasi-steady state stability maps in the dimensionless stability plane through frequency domain analysis and experimental tests provides the state-of-the-art methodology of analyzing the flow instability. Experimental startup instability during different initial startup procedures is reviewed. Although extensive efforts have been made to study the flow instability, further work is required to improve the scaling ability of experimental investigation and the accuracy of code analysis. Some discussions for future research directions are given.
\end{abstract}

\section{Keywords}

Startup flow instability, Natural circulation driven, Stability maps 


\section{Introduction}

The boiling water reactors (BWR) generate around $20 \%$ of overall nuclear electricity based on the IAEA data in 2015. The BWRs in operation are mainly designed by General Electric (GE) including generations from BWR/1 to BWR/6 in the US. Since 1980s, GE also developed advanced boiling water reactor (ABWR), simplified boiling water reactor (SBWR), and economic simplified boiling water reactor (ESBWR). Apart from the conventional BWRs, some small modular reactors (SMRs) are also in fast development by taking advantage of mature boiling water technology, such as the Mitsubishi's integrated modular water reactor (IMR) with a thermal output of $1000 \mathrm{MW}$ [1], and Purdue's novel modular reactor (NMR-50) with a thermal output of $165 \mathrm{MW}$ [2]. The design of reactors mentioned above except for the BWRs/1 6 eliminate the recirculation loops and pumps by utilizing natural circulation to provide the driving force, which is induced by the density difference between the hot leg and cold leg. However, the driving force for the natural circulation is especially weak when the system pressure or power level is low. Flow instability has been widely observed and investigated during the initial startup transients or accidental scenarios for natural circulation driven water reactors. Three flow instability mechanisms, i.e., density wave oscillations (DWOs), flashing instability, condensation induced flow instability (Geysering instability), has been mostly reported and studied through both theoretical analyses and experimental tests.

This paper aims to provide deep insights of the flow instabilities especially in natural circulation driven water reactors. Section 2 describes the flow instability mechanisms. Section 3 presents the popular analysis methods. Section 4 introduces the scaling methods and analysis to build test facility to study flow instability experimentally. Section 5 presents the theoretical and experimental methods to obtain the steady state stability maps. Section 6 introduces existing research on the flow instability during the startup transients. And the key conclusions are summarized in Section 7.

\section{Major flow instabilities encountered in boiling-type nuclear reactors}

\subsection{Density wave oscillations in normal operations}

The most common dynamic flow instability in the two-phase flow system is the density wave oscillation, which is also named as thermally induced flow instability caused by kinematic- 
wave (density wave) propagation [3,4]. The mechanism of the DWOs in a single heated channel can be explained through Fig. 1. If the inlet flow is perturbed sinusoidally, the change of mixture density will be delayed due to the existence of the time-lag effects (residence time) in both single-phase and two-phase flow. Then local pressure drop fluctuates in a similar pattern but also with certain time delays due to the propagation of density waves. In certain conditions, the total pressure drop of the heated channel can be 180 degree out-of-phase with respect to the inlet flow velocity. As can be seen in Fig. 1, the biggest channel pressure drop can correspond to the smallest inlet flow velocity, which is considered unstable. Sustained oscillations occur if a selfexciting relation is satisfied between the inlet flow velocity and internal pressure drop. The detailed analysis of the DWOs can be found in a report [5]. The procedures to avoid DWOs have been developed based on the quasi-steady state stability maps. Various parameters affecting the boundary of the stability can be analyzed using the stability maps [3]. For example, adding the flow resistance ( $\mathrm{K}$ factor) at the channel inlet is an effective method to prevent the DWOs.

Fig. 1. Density wave oscillations

\subsection{Flashing instability during the initial startup transients}

The flashing instability has been widely investigated during the normal initial startup procedures for natural circulation boiling water reactors (NCBWRs). The flashing instability occurs due to the design of a long chimney section to enhance the driving force in NCBWRs. Under low system pressures, the saturated coolant at the top of the heated section becomes superheated when it flows upward due to reduced hydrostatic head in the relatively long chimney above the core. The evaporation of the superheated coolant increases significantly the void fraction to raise the natural circulation flow rate. However, the suddenly increased flow velocity can bring in large amount of subcooled coolant into the active heated region from the downcomer causing the reduction of the driving force. Therefore, the natural circulation flow rate can experience many intermittent flow oscillations before the flashing is completely suppressed under high system pressure [6]. The flashing instability disappears when the system pressure beyond certain value, which is $0.5 \mathrm{MPa}$ confirmed by many researchers. The quantification of the flashing instability can be addressed by a properly defined flashing number. 
In addition, the flashing instability can be avoided by using either very slow power ramp rate or pressurized startup procedures.

\subsection{Condensation induced flow instability during the initial startup transients}

The condensation induced flow instability $[7,8]$ is also named as the Geysering instability, which is quite opposite to the flashing instability regarding to the flow instability phenomena. It usually happens in the upper plenum near the core exit. The bubbles generated in the core section can experience subcooled conditions in the upper plenum under low pressure conditions. Therefore, the bubbles collapse to increase the local temperature and change the mixture flow velocity. The Geysering instability can be observed during the startup transients, during which subcooled conditions are dominant at low pressure and low power levels. The Geysering instability disappears once saturated conditions are developed with increased system pressure. Therefore, similar to the flashing instability, the Geysering instability can be avoided by using the pressurized startup procedures.

\section{Analysis method}

For the BWR stability analysis, there are generally two widely used analytical approaches to investigate the flow instability: frequency domain analysis and time domain analysis. The neutronics models are usually coupled with thermal-hydraulic models to study the flow instability in both methods.

Frequency domain analysis: Most of the field equations describing the system dynamics are complicated non-linear partial differential equations. These non-linear equations can be turned into linear conservative equations in the frequency domain. Therefore, it is also called linear frequency domain stability analysis. The system governing equations are linearized by small perturbation about steady-state, and transfer functions can be obtained between perturbed variables. Due to simplifications of the linearization, the frequency domain analysis can be used to obtain the stability boundary, i.e., the onset of flow instability, for the density wave oscillations based on certain stability criterion. The frequency domain analysis codes include FABLE/BYPSS, HIBLE, LAPUR-5, NUFREQ [9, 10] etc. The general approach of the frequency domain analysis of the density wave oscillations is introduced as follows. 
The system of interest consists of four components, i.e., upstream single-phase unheated section, single-phase heated section, two-phase heated section, and downstream two-phase unheated section. The problem is formulated in terms of the drift-flux model accounting for the relative velocity between two phases [11]. The formulation of the drift-flux model includes four field equations and several constitutive equations. By using small perturbations, a characteristic equation is obtained between the perturbation of the total pressure drop and perturbation of the inlet velocity.

$$
\delta v=\frac{1}{Q(s)} \delta \Delta P_{e x}
$$

where $Q(s)$ is the characteristic equation. According to control theory, the asymptotic stability of the system can be determined by nature of roots of the characteristic equation given by

$$
Q(s)=0
$$

The characteristic equation can be formulated in a series of dimensionless numbers as

$$
Q\left(s^{*}, \alpha_{1}, \alpha_{2}, \cdots, \alpha_{n}\right)=0
$$

where $\alpha_{1}$ to $\alpha_{n}$ are independent dimensionless numbers. For the reactor stability analysis, the dimensionless phase change number (Zuber number) and subcooling number at the inlet are chosen in the stability plane [3]. If the harmonic oscillations are considered, system response can be obtained by substituting $s^{*}=j \omega^{*}$ into Eq. (3) as

$$
Q\left(j \omega^{*}, N_{p c h}, N_{s u b}\right)=Q_{\mathrm{Re}}\left(\omega^{*}, N_{p c h}, N_{s u b}\right)+j Q_{\mathrm{Im}}\left(\omega^{*}, N_{p c h}, N_{s u b}\right)=0
$$

Thus, Eq. (4) reduces to

$$
\begin{aligned}
& Q_{\mathrm{Re}}\left(\omega^{*}, N_{p c h}, N_{s u b}\right)=0 \\
& Q_{\mathrm{Im}}\left(\omega^{*}, N_{p c h}, N_{s u b}\right)=0
\end{aligned}
$$

Eqs. (5) and (6) give the harmonic frequency surfaces in the dimensionless plane of $N_{\text {sub }}{ }^{-}$ $N_{p c h}$. In addition, the D-partition method states that the number of roots lying in the right half $s^{*}$ plane for each region divided by surfaces do not change within a subdivision. Since the stability 
curve is determined, the stability of each region can be determined by testing the stability at any point in that region using certain stability criteria, such as Mikhailov criterion used by Ishii [3].

In addition, Ishii obtained the similarity groups from the non-dimensionalized field equations and constitutive equations [3]. Those similarity groups later developed into the dimensionless numbers for the scaling analysis in the three-level scaling method. Various parameters, such as the heat flux, inlet subcooling, inlet flow velocity, system pressure, inlet and exit orificing, were investigated on the prediction of stability boundary. Furthermore, the effects of non-uniform heat flux, relative velocity, and static and dynamic friction factor were discussed.

Saha [12] extended Ishii's work and incorporated the effects of the thermal non-equilibrium. A new general correlation was found to determine the point of net vapor generation for a boiling channel with inlet subcooling. Compared to Ishii's thermal equilibrium model, the obtained stability boundary predicted a more stable system at low subcooling number, and a more unstable system at high subcooling number. Kuran [13] took account of the void reactivity feedback later in the linear stability analysis for the NCBWR.

Following Ishii's approach to obtain the stability boundary for the DWOs, Shi [14] considered the flashing phenomena at the top of the chimney at low pressure as an axially uniform heat source in the frequency domain analysis under thermal equilibrium conditions. The kinematic and dynamics of the downstream unheated mixture region were obtained. The predicted stability boundaries were compared with quasi-steady state experimental data. The flashing boundary and density wave oscillations boundaries could be predicted in the dimensionless stability plane. Although the theoretical flashing boundary showed some discrepancy with the experimental data, the effect of system pressure and inlet $\mathrm{K}$ factor were able to be correctly predicted.

Time domain analysis: Compared to the frequency domain analysis, the time domain analysis has been also widely used to solve the non-linear partial differential equations to study the flow behavior once the neutral stability boundary is crossed. Several time domain analysis codes have been developed, such as RAMONA-3B, RELAP5/3D, RETRAN-3D, TRACG and TRACE etc. The detailed description of these codes including some frequency domain analysis codes can be found in D'Auria's paper [9].

$\mathrm{Su}$ et al. performed time domain analysis on the DWOs of two-phase natural circulation under low quality conditions using code NTDCC [15]. The obtained marginal stability 
boundaries (MSBs) of two low temperature heating reactors agreed well with experimental data. $\mathrm{Hu}$ [16] performed Ringhals-1 stability analysis by TRACE/PARCS code and the results were benchmarked against the analysis from the frequency domain analysis code STAB. The author pointed out that both codes had large uncertainties. Frequency domain approach was fast and efficiently applied to conduct parametric sensitivity study, whereas time domain analysis code was time consuming and had the concern about numerical diffusion. Therefore, no matter what kind of analysis methods, the further development of analysis codes needs to be verified and validated against the high-quality experimental data sets to reduce the uncertainties in the stability predictions. In the following sections, the scaling methodology, test facility design, and existing stability data sets are reviewed.

\section{Scaling methodology to design modeled test facilities}

\subsection{Natural circulation SBWR test facility}

GE's SBWR-600 [17] has been considered as a prototype reactor for the study of natural circulation flow instability in a traditional nuclear reactor. The SIRIUS-N (SImulated Reactivity feedback Incorporated into thermal-hydraUlic Stability for Natural circulation BWR) facility $[18,19]$, which consists of two channels, two chimneys, an upper plenum, a downcomer, a subcooler, and a preheater, was designed and built to study the flow instability for the SBWR. The scaling analysis [20] for the SIRIUS-N test facility came from the non-dimensional numbers, i.e., Froude number, Euler number, flashing number, phase change number, subcooling number etc., for thermal-hydraulic similarity at two pressures including normal operating pressure and test pressure [20, 21]. Most non-dimensional parameters were similar to those of the prototype reactor. However, the flashing number and the Froude number were around $70 \%$ of the values in the prototype reactor due to $70 \%$ of the prototype core channel length, which was $1.7 \mathrm{~m}$ in the SIRIUS test facility [18].

In addition, Woo also studied the flow instability in the natural circulation boiling water reactor based on the three-level scaling method developed to design Purdue University MultiDimensional Integral Test Assembly (PUMA) for GE SBWR by Ishii et al. [22]. Instead of using parallel channels in the SIRIUS-N test facility, one channel with single electric heating rod was utilized to simulate the core section [23]. The scaling analysis was performed under the prototypic pressure to maintain the similarity in the geometric, kinematic, dynamic, and 
energetic parameters. In addition, the neutron kinetics and fuel dynamics were coupled with single and two-phase thermal hydraulics to design a test facility with a length ratio of $1 / 3$ between the test facility and the prototype. The total height of the test facility was $5.25 \mathrm{~m}$ and the core flow area was $4.582 \mathrm{~cm}^{2}$. Considering most interested instability problems during the startup transients occurred at pressures below 1.0 MPa, the maximum sustainable pressure of the test facility was designed at $1.0 \mathrm{MPa}$.

\subsection{Purdue IMR test facility}

The Purdue integral modular water reactor test facility [24] was built to study the natural circulation flow stability for the IMR. The scaling analyses were also based on the three-level scaling analysis by using dimensionless numbers. However, the low-pressure phenomena like flashing instability due to the reduced hydrostatic head and coupled flow/power behavior due to the void-reactivity feedback were included in the scaling analysis. The length ratio of the IMR test facility was $1 / 3.23$. And the area ratio was about $6.06 \times 10^{-4}$. Regarding to the core channel design, four electric heating rods were installed in the core part to simulate the IMR fuel assemblies. Compared to the single-heating rod, multi-heating rods can induce more uniform boiling radially. Therefore, the flashing instability in the chimney section was much similar to that in the prototype.

\subsection{Purdue NMR test facility}

The Purdue NMR test facility was also designed and built based on the three-level scaling methodology. The scaling analysis was also performed according to those dimensionless numbers. In addition, the RELAP5 analysis [6] was utilized to examine the accuracy of the scaling analysis during startup transients and quasi-steady state states. Based on previous experiences, the magnitude of the flashing instability was mainly determined by the height of the chimney section. Therefore, the length ratio of the NMR test facility to the NMR-50 was 1/1.2 after considering the ceiling height. The total height of the test facility was about $7 \mathrm{~m}$, which was very close to that of the prototypic design of the NMR-50 reactor [2]. Due to the limitation of the lab space, the area ratio between the model and the prototype was close to 1/1000. Four electric heaters were installed in the core section. In addition, the core inlet flow resistance ( $\mathrm{K}$ factor) was calibrated to keep the similarity of the natural circulation flow rate in the loop under normal 
operating conditions. Finally, the scaling analysis of the mass inventory for the coolant and structure were analyzed with thermal inertia number. Proper heat compensations for the structures were applied to reduce the power scaling distortions in the core section due to large heat transferred to the structures. Without those compensations, the time scale could be significantly distorted from the prototype during the startup transients.

\section{Steady state stability maps}

\subsection{Stability plane}

The steady state stability map is beneficial to understand the mechanism of the flow instability by performing parametric studies on system pressure, inlet flow resistance, and drift velocities etc. The steady state stability map is generated in the stability plane of dimensionless subcooling number and phase change number (Zuber number), which are defined by [3]

$$
\begin{gathered}
N_{p c h}=\frac{\dot{Q}}{\dot{m}_{o}} \frac{\Delta \rho}{\rho_{g} \Delta i_{f g}} \propto \frac{\text { core enthalpy rise }}{\text { latent heat }} \\
N_{s u b}=\Delta i_{s u b} \frac{\Delta \rho}{\rho_{g} \Delta i_{f g}} \propto \frac{\text { core inlet subcooling }}{\text { latent heat }}
\end{gathered}
$$

where $\dot{Q}$ and $\dot{m}_{0}$ identify the total heat transfer rate and coolant flow rate in the heated section, respectively. Other symbols in the above set of equations conform to standard nomenclature. The relations between the phase change number and subcooling number can be derived from the dimensionless energy equation at steady state by

$$
N_{p c h}-N_{s u b}=x_{e} \frac{\Delta \rho}{\rho_{g}}
$$

where $x_{e}$ denotes the core exit quality. And the length of non-boiling region is given by

$$
\lambda^{*}=\frac{N_{s u b}}{N_{p c h}}
$$

The basic characteristics of the stability plane in Eq. (9) are illustrated in Fig. 2.

Fig. 2. Stability plane [3] 
The stability plane was firstly applied by Ishii [3] to determine the stability boundary for the density wave oscillations in a heated system using perturbation method. Now it has been widely accepted as a standard tool to analyze different flow instabilities. The steady state stability map can be obtained by performing either frequency domain analysis or the quasi-steady state experimental tests.

\subsection{SBWR experimental stability maps}

The experimental stability maps can be obtained from the quasi-steady state tests. The test matrix design is required to cover the operating conditions in the dimensionless stability plane. Certain stability criterion is used on the flow velocity to determine if it is stable or not. Instead of using dimensionless phase change number, some researchers use the core heat flux in the stability plane for the convenience. However, these two different stability maps can be switched over each other based on Eq. (7).

Furuya plotted the experimental stability maps in the dimensionless plane of the channel inlet subcooling number and core heat flux at different system pressures ranging from 0.1 to 0.5 MPa [18]. Intermittent flow oscillations were mainly observed at the pressure of $0.1 \mathrm{MPa}$, while sinusoidal oscillations were only observed at 0.35 and $0.5 \mathrm{MPa}$. At 0.2 $\mathrm{MPa}$, intermittent oscillations occurred at high subcooling region, while sinusoidal oscillations occurred at low subcooling region. As can be seen from Fig. 3, unstable flow regions were surrounded by the solid lines. And the unstable flow region reduced with increasing system pressure. In addition, the unstable flow region shifted to the higher heat flux when the pressure increased. It was suggested that both intermittent oscillations and sinusoidal oscillations were flashing induced density wave oscillations, since the oscillation period was related to the passing time of singlephase liquid in the chimney.

Fig. 3. Furuya's SBWR stability map at $0.1,0.2,0.35$, and $0.5 \mathrm{MPa}[21]^{1}$

Fig. 4 shows Woo's experimental stability map in the stability plane of the inlet subcooling number against the core heat flux [23]. Compared to Furuya's SBWR stability map in Fig. 3, the stability boundaries did not show significant differences in general trends. However, the core inlet subcooling number in Woo's stability map did not go below zero due to test limitations. 
Therefore, no stability boundary at low subcooling number was plotted in the stability plane under 0.1 MPa. In addition, intermittent oscillations were observed at high subcooling region, while sinusoidal oscillations were observed at low subcooling region at different pressures. Woo considered that both low frequency intermittent oscillations and high frequency sinusoidal oscillations were characterized as a low quality gravity-driven Type-I instability, which was proposed by Fukuda and Kobori [25].

Fig. 4. Woo's SBWR stability map at 0.1, 0.2, 0.3, and 0.4 MPa [23]

\subsection{IMR experimental stability maps}

Fig. 5 presents the IMR's steady state stability map [24], which was plotted in the standard dimensionless plane of the core inlet subcooling number against the phase change number $\left(N_{s u b^{-}}\right.$ $\left.N_{p c h}\right)$ with zero quality lines at the core exit and the chimney exit. The difference between two zero quality lines was characterized by the flashing number. One standard stability map shown in Fig. 5 was actually transferred from the stability map plotted in the stability plane of core inlet subcooling number and core heat flux, which was similar to those maps for the SBWR. As can be seen, the first boundary between the stable conditions and unstable conditions at high subcooling region is close to the zero quality line at the core exit. In addition, the effect of system pressure on the flow instability was investigated under a pressure rang of 0.2 to $1 \mathrm{MPa}$. At higher pressure, the stable region enlarged due to reduced flashing effect and lower density difference between liquid and vapor. Therefore, all operating conditions were stable under the pressure of 1.0 MPa [26].

Fig. 5. IMR stability map at 0.2 MPa [24]

\subsection{NMR-50 experimental stability maps}

The quasi-steady state tests for the NMR-50 were performed in a newly designed and wellscaled integral test facility [27]. Similarly, the same amount of testing points was plotted again in the non-dimensional plane with the zero quality line at the core exit in Fig. 6. From Eq. (9), the subcooling number was equal to the phase change number along the zero quality line at the core exit. In the stability map under $0.2 \mathrm{MPa}$, most transition points were located above the zero 
quality line except few unstable transient points, which meant that flow transitions occurred in the thermal non-equilibrium conditions. The flashing in the chimney due to reduced hydrostatic head led to the intermittent flashing oscillations. At low pressure, both the flashing in the chimney and the boiling in the core section determined the development of two-phase natural circulation.

If one group of data for certain core heat flux was carefully investigated, the change of phase change number was not sensitive to the decreasing of subcooling number during the single-phase natural circulation (high subcooling region). However, the phase change number reduced substantially when the coolant in the core section started to boil. The two-phase natural circulation in the stability map was separated from the single-phase natural circulation by the zero quality line (green dash line in Fig. 6) at the chimney exit under 0.2 MPa. The two-phase natural circulation testing conditions were in the low phase change number region due to larger natural circulation rate compared to that of single-phase natural circulation. The time trace of natural circulation rate at three phases could be seen in Fig. 7. For both the single-phase and twophase natural circulation, the core inlet flow velocities were stable. However, the flow velocity experienced big fluctuations during the transition phase due to the flashing instability. The density wave oscillations observed during the startup transients were not able to be investigated for the following two reasons. First, the density wave oscillations might exist for a very short time, current test strategy cannot determine the unstable density wave oscillations. Secondly, even if density wave oscillations existed, the boundary was hard to draw due to the experimental testing conditions in the stability map moving to the low subcooling number and low phase change number region. In other words, the density wave oscillations were not a dominant instability mechanism at low pressure conditions for natural circulation test facilities or reactors.

Fig. 6. NMR-50 stability map at $0.2 \mathrm{MPa}$ [27]

Fig. 7. Core inlet flow velocity profile at different phases [27]

\section{Startup flow instabilities}

The flow instability are prone to occur during the normal initial startup procedures in the natural circulation driven water reactors. Based on the quasi-steady state stability maps, the 
flashing instability is dominant at low pressure conditions due to the variations of saturation temperature along the chimney. In this section, startup flow instability are reviewed based on the experimental results from three types of reactors.

\subsection{SBWR startup instability}

The SBWR startup flow instability during normal startup procedures was performed by Woo [23]. Usually, the core inlet flow velocity and void fraction profile can be used to investigate the flow instability. During the startup transients in real reactor, the reactor power is increased by withdrawing the control rods. However, the heating power is given in the control system when tests are performed in a test facility. Fig. 9 shows system pressure inside steam dome for the fast startup transients using the power ramp rate as shown in Fig. 8. The temperature increasing rate was about $55^{\circ} \mathrm{C}$ per hour. As can be seen, it took about $6000 \mathrm{~s}$ for the system pressure to reach 0.8 MPa. Some fluctuations could be observed before $3500 \mathrm{~s}$, which corresponded to the flow velocity oscillations shown in Fig. 10. The time trace of flow velocity profile was composed of stable single-phase natural circulation, flashing near the separator, intermittent oscillations, sinusoidal oscillations, and stable two-phase natural circulation. As can be seen, the natural circulation rate continuously increased as the power escalated. Although there were some weak oscillations caused by flashing near the separator or top of the chimney, the initial 800 seconds was considered as stable single-phase natural circulation by Woo. After the single-phase natural circulation, intermittent oscillations due to the flashing in the chimney occurred at relatively low pressure. As power and pressure increased, the low frequency intermitting flow oscillations turned to sinusoidal oscillations. At the end, the two-phase flow velocity stabilized at high pressure. Fig. 11 shows the void fraction profile at the core exit. The intermitting oscillations

caused by flashing instability can be observed from 800 to $3000 \mathrm{~s}$. The sinusoidal oscillations caused by density wave oscillation were negligible in this case.

Fig. 8. Power curve for the fast startup transients for the SBWR $\left(55^{\circ} \mathrm{C} / \mathrm{hour}\right)[23]$

Fig. 9. Steam dome pressure for the fast startup transients for the SBWR [23]

Fig. 10. Core inlet velocity for the fast startup transients for the SBWR [23] 
S. Shi, T. Hibiki, and M. Ishii/ Startup Instability in Natural Circulation Driven Nuclear Reactors

Fig. 11. Void fraction at the core exit for the fast startup transients for the SBWR [23]

\subsection{IMR startup instability}

Dixit also performed the startup transient tests for the IMR to study the startup flow instability [28]. The power curve used in the IMR test facility was a little bit different from that used by Woo. It was switched to a different power ramp rate when the system pressure reached 0.5 MPa. In addition, the power curve in Fig. 12 took into account of the power used to increase the solid heat structure temperature in the single-phase natural circulation and the heat loss to the environment. Therefore, the electric heater power was larger than the scaled power in the singlephase region. The steam dome pressure shown in Fig. 13 was initially constant in the singlephase natural circulation and it increased exponentially after the start of boiling during the fast startup transients for the IMR. The time required to reach the pressure of $0.5 \mathrm{MPa}$ was about 6 hours. Density wave oscillations and condensation induced flow instability were observed during the fast startup transient tests. The core inlet velocity profile was presented in Fig.14, where the density wave oscillations could be clearly recognized based on the periods of oscillations. The increased system pressure would stabilize the flow rate due to low density difference between vapor and liquid, and reduced flashing in the chimney.

Fig. 12. Power curve for the fast startup transients for the IMR [28]

Fig. 13. Steam dome pressure for the fast startup transients for the IMR [28]

Fig. 14. Core inlet velocity for the fast startup transients for the IMR [28]

\subsection{NMR-50 startup instability}

Based on the experiences from above mentioned startup transient tests, a new natural circulation test facility was built to investigate the natural circulation flow instability under low pressure and low power conditions [6, 29]. As mentioned above, the scaling distortions between the model facility and the prototype were carefully addressed to guarantee the accuracy of the startup transient tests. Therefore, the scaled linear power curve in Fig. 15 was able to be directly 
applied in the transient tests. During the startup tests, the flashing instability was the main flow instability mechanism observed at low pressure conditions. Density wave oscillations were recognized at relatively high pressure. However, the density wave oscillations disappeared when pressure increased. The condensation induced flow instability, which was also named as Geysering instability, was also observed in the chimney near the core exit but was negligible.

Figs. 16 to 18 show the time profile of the system pressure, natural circulation velocity at the core inlet, and the detailed void fraction at the core exit during the fast startup transients for the NMR-50. The single-phase natural circulation phase in Fig. 17 was from 0 to 25 minutes and ended with the big velocity peak caused by the flashing in the chimney due to long residence time of the coolant in the core section. In addition, a big variation of temperature along the chimney could be observed before the flashing. The periodic flashing continued with few smaller velocity fluctuations from 25 to 60 minutes. Intermittent oscillations caused by the flashing were continuously observed in the net vapor generation phase, which was from 60 to 75 minutes. The period of the flashing oscillations during the net vapor generation phase was about 5 minutes. The differences in the amplitudes and patterns of void fraction fluctuations between the flashing instability and the density wave oscillations were very clearly shown in Fig. 18.

Fig. 15. Power curve for the fast startup transients for the NMR-50 [6]

Fig. 16. Steam dome pressure for the fast startup transients for the NMR-50 [6]

Fig. 17. Natural circulation rate for the fast startup transients for the NMR-50 [6]

Fig. 18. Detailed void fraction at the core exit for the fast startup transients of the NMR-50 [6]

\section{Conclusions}

\subsection{Void reactivity feedback on the flow instability}

In BWRs, the water is used as coolant as well as moderator. The core power is determined by the neutron flux which strongly depends on the void fraction. Therefore, the void reactivity feedback between the neutron flux and the void fraction has been studied especially after several nuclear power plant events reported during the 1980s. The point-kinetics model can be used to 
calculate the power needed during the startup transients for a simple approach. The nuclearcoupled flow instability tests strongly require very accurate void fraction measurement in the transients. In addition, the fuel dynamics should be addressed by the time constant parameter between the fuel rods and electric heaters. The above mentioned authors in this paper also investigated the nuclear-coupled flow instability mechanism during the startup transients or the quasi-steady state tests. The results show that current natural circulation driven BWRs have sufficiently large stability margin during the startup transients and normal operations, even with void reactivity feedback taken into account. However, the void reactivity feedback on the flow instability is complicated and it might destabilize the system in some other cases [30, 31$]$.

\subsection{Consideration on the scaling analysis and scaling distortions on the transient tests}

The scaling analysis method affects the similarity of the final experimental results. Although most test facilities are scaled down from the prototype using non-dimensional numbers, the scaling uncertainties can be varied among different test facilities. The scaling distortions affecting the flow instability mainly come from following aspects.

1) The height of the test facility. The natural circulation driven nuclear reactors feature a relatively long chimney to enhance the driving force. However, it is very difficult to design and build a full-height test facility in the lab. Therefore, the flashing instability observed in reduced-height test facility must be less significant than that in the prototype. It is recommended that a well-validated frequency domain analysis code based on the test results should be applied to the prototype to investigate the flashing instability.

2) The number of flow channels in the heated section. Single channel can't reflect the core geometry in real reactors, which usually have several flow channels corresponding to the non-uniform radial power distributions. Two channels were used in the SIRIUS test facility, which might bring in the flow instability caused by parallel channels. Four channels are used to study the flow instability for the IMR and the NMR. It is recommended to have several core flow channels to study the regional flow instability by taking into account of the void reactivity feedback.

3) The flow resistance distribution. For a natural circulation loop, the flow resistance is balanced with the driving force induced by the density difference between the riser and downcomer. Therefore, the $\mathrm{K}$ factor distributions at the core inlet, spacer grids, and core 
outlet needs to be carefully calibrated. Based on Ishii's stability analysis [3], increasing core inlet $\mathrm{K}$ factor tends to stabilize the flow, while increasing core outlet $\mathrm{K}$ factor tends to destabilize the flow. It is recommended to maintain the similarity of the flow resistance in the core section by performing separate calibrations and a whole loop calibration [6].

4) The mass structure of the test facility. The extra structures, i.e., pipe connection flanges, measurement ports, and different valves etc., of the test facility could largely surpass the total structure mass based on the scaling analysis for a largely scaled down facility. These extra mass structures can significantly affect the experimental results during the transient tests. It is not recommended to simply add a compensating power to the core heaters, which could affect the local heat transfer very easily. A better method is to add extra heater power in the loop to increase the structure temperature using PID controller during the startup transients [6].

\subsection{Startup procedures to eliminate the flow instability}

Regarding to eliminate the flashing instability during the initial startup process, two approaches have been investigated and agreed. First approach is to use very slow power ramp rate before stable two-phase natural circulation flow can be established [14]. This method takes much longer time than normal startup procedures. Although the very slow startup transients can't eliminate flow instability completely, the magnitude of the oscillations are significantly reduced. Considering the conservative assessment from the experimental results, the very slow startup procedures could be an option applied in real natural circulation driven reactors. The second approach is to use pressurized startup procedure for the initial startup transients. Based on this approach, two possible ways to pressurize the reactor have been proposed. One way is to pressurize the steam dome pressure by creating a steam cushion in the region of steam separator without using external components [32]. But the flashing is allowed at the top of the riser to increase the system pressure. The other way is to pressurize the reactor with the non-condensable gas such as nitrogen to certain pressure at the very beginning [33, 34]. This way requires an extra degassing procedure when the system pressure reaches certain pressure such as $0.5 \mathrm{MPa}$.

\subsection{Theoretical stability maps}


Although general stability boundary can be predicted with the stability plane, most stability maps obtained in either frequency domain or time domain still have large uncertainties. The uncertainties exists in mechanistic models and correlations, assumptions, and numerical methods used in the analysis of various categories of flow instability, and can be propagated to the prediction of the stability boundary. Therefore, the uncertainties of the theoretical stability boundary need to be quantified and benchmarked against high-quality instability experimental data in both quasi-steady state and transient scenarios.

In the future, the investigation of natural circulation flow instability should focus on the regional flow instability by taking into account of void reactivity feedback. In order to get highquality experimental data, proper scaling analysis method with scaling distortions management, and accurate void fraction measurement technique with quantified uncertainty should be considered.

\section{Acknowledgements}

This material is based upon work supported under a Department of Energy Nuclear Energy University Program. In addition, the authors would like to express their special thanks to Drs. Masahiro Furuya and Kyoungsuk Woo for giving the permission to use their figures in their Ph.D. theses.

\section{References}

[1] K. Hibi, H. Ono, and T. Kanagawa, "Integrated modular water reactor (IMR) design," Nuclear Engineering and Design, 230 (1-3), pp. 253-266, May 2004.

[2] M. Ishii, S. Shi, W. S. Yang, Z. Wu, S. Rassame, and Y. Liu, "Novel modular natural circulation BWR design and safety evaluation," Annals of Nuclear Energy, 85, pp. 220-227, Nov. 2015.

[3] M. Ishii, "Thermally induced flow instabilities in two-phase mixtures in thermal equilibrium," (Dissertation), Georgia Institute of Technology, 1971.

[4] M. Ishii, "Study on flow instabilities in two-phase mixtures," ANL-76-23, Argonne National Lab., IL USA, 1976. 
S. Shi, T. Hibiki, and M. Ishii/ Startup Instability in Natural Circulation Driven Nuclear Reactors

[5] J. March-Leuba, "Density-wave instabilities in boiling water reactors," Nuclear Regulatory Commission, Washington, DC (United States). Div. of Systems Technology; Oak Ridge National Lab., TN USA, 1992.

[6] S. Shi, J. P. Schlegel, C. S. Brooks, Y.-C. Lin, J. Eoh, Z. Liu, Q. Zhu, Y. Liu, T. Hibiki, and M. Ishii, "Experimental investigation of natural circulation instability in a BWR-type small modular reactor," Progress in Nuclear Energy, 85, pp. 96-107, Nov. 2015.

[7] M. Aritomi, J. H. Chiang, T. Nakahashi, M. Wataru, and M. Mori, "Fundamental study on thermo-hydraulics during start-up in natural circulation boiling water reactors, (I). Thermohydraulic instabilities," Journal of Nuclear Science and Technology, 29 (7), pp. 631-641, 1992.

[8] M. Aritomi, J. H. Chiang, and M. Mori, "Geysering in parallel boiling channels," Nuclear Engineering and Design, 141 (1-2), pp. 111-121, Jun. 1993.

[9] F. D’Auria, A. L. Costa, and A. Bousbia-Salah, "The boiling water reactor stability," IAEA-TECDOC-1474, Annex 10, 2005.

[10] G. Su, D. Jia, K. Fukuda, and Y. Guo, “Theoretical and experimental study on density wave oscillation of two-phase natural circulation of low equilibrium quality," Nuclear Engineering and Design, 215 (3), pp. 187-198, Jun. 2002.

[11] M. Ishii, "One-dimensional drift-flux model and constitutive equations for relative motion between phases in various two-phase flow regimes," Argonne National Lab., IL USA, 1977.

[12] P. Saha, "Thermally induced two-phase flow instabilities, including the effect of thermal non-equilibrium between the phases," (Dissertation), Georgia Institute of Technology, 1974.

[13] S. Kuran, "Modeling and simulation of coupled flow/power behavior in low pressure natural circulation systems," (Dissertation), Purdue University, West Lafayette, IN, 2006.

[14] S. Shi, "Investigation of Natural Circulation Instability and Transients in Passively Safe Novel Modular Reactor,” (Dissertation), Purdue University, West Lafayette, IN, 2015.

[15] G. Su, D. Jia, K. Fukuda, and Y. Guo, "Theoretical Study on Density Wave Oscillation of Two-Phase Natural Circulation under Low Quality Conditions," Journal of Nuclear Science and Technology, 38 (8), pp. 607-613, Aug. 2001.

[16] R. Hu, "Stability analysis of the boiling water reactor : methods and advanced designs," (Dissertation), Massachusetts Institute of Technology, Cambridge, MA, 2010.

[17] G. N. Energy, "SBWR standard safety analysis report," Report 25A5113 revd. A, 1992. 
[18] M. Furuya, F. Inada, and T. H. J. J. van der Hagen, "Flashing-induced density wave oscillations in a natural circulation BWR - mechanism of instability and stability map," Nuclear Engineering and Design, 235 (15), pp. 1557-1569, Jul. 2005.

[19] M. Furuya, F. Inada, and T. H. J. J. Van der Hagen, "Development of SIRIUS-N facility with simulated void-reactivity feedback to investigate regional and core-wide stability of natural circulation BWRs," Nuclear Engineering and Design, 235 (15), pp. 1635-1649, Jul. 2005.

[20] F. Inada, M. Furuya, A. Yasuo, H. Tabata, Y. Yoshioka, and H. T. Kim, "Thermohydraulic instability of natural circulation BWRs at low pressure star-up. Experimental estimation of instability region with test facility considering scaling law," in Proceedings of the 3rd JSME/ASME joint international conference on nuclear engineering, 1, pp. 173-178, 1995.

[21] M. Furuya, "Experimental and analytical modeling of natural circulation and forced circulation BWRs: thermal-hydraulic, core-wide, and regional stability phenomena," (Dissertation), TU Delft, Delft University of Technology, Netherlands, 2006.

[22] M. Ishii, S. T. Ravankar, and R. Dowlati, "Scientific design of Purdue University MultiDimensional Integral Test Assembly (PUMA) for GE SBWR,” NUREG/CR-6309, Apr. 1996.

[23] K. Woo, "Experimental and analytical study of stability characteristics of natural circulation boiling water reactors during startup transient," (Dissertation), Purdue University, West Lafayette, IN, 2008.

[24] A. Dixit, T. Hibiki, M. Ishii, K. Tanimoto, Y. Kondoh, and K. Hibi, "Experimental stability maps for a two-phase natural circulation reactor with and without void-reactivity feedback effect," Nuclear Engineering and Design, 261, pp. 181-200, Aug. 2013.

[25] K. Fukuda and T. KOBORI, "Classification of two-phase flow instability by density wave oscillation model," Journal of Nuclear science and Technology, 16 (2), pp. 95-108, 1979.

[26] A. Dixit, "Stability of two-phase natural circulation reactor during start-up procedures," (Dissertation), Purdue University, West Lafayette, IN, 2010.

[27] S. Shi, Y.-C. Lin, W. S. Yang, and M. Ishii, "Experimental stability maps for a BWR-type small modular reactor," in International Topical Meeting on Nuclear Reactor Thermal Hydraulics NURETH-16, Chicago, IL, 2015.

[28] A. Dixit, T. Hibiki, M. Ishii, K. Tanimoto, Y. Kondoh, and K. Hibi, "Start-up transient test simulation with and without void-reactivity feedback for a two-phase natural circulation reactor," Nuclear Engineering and Design, 265, pp. 1131-1147, Dec. 2013. 
[29] S. Shi, Z. Wu, Z. Liu, J. P. Schlegel, C. S. Brooks, J. Eoh, Y. Yan, Y. Liu, W. S. Yang, and M. Ishii, "Experimental investigation of natural circulation instability with void-reactivity feedback during startup transients for a BWR-type SMR,” Progress in Nuclear Energy, 83, pp. 73-81, Aug. 2015.

[30] Y. F. Rao, K. Fukuda, and R. Kaneshima, "Analytical study of coupled neutronic and thermodynamic instabilities in a boiling channel," Nuclear Engineering and Design, 154 (2), pp. 133-144, Mar. 1995.

[31] D. D. B. van Bragt and T. Van der Hagen, "Stability of natural circulation boiling water reactors: Part II - Parametric study of coupled neutronic-thermohydraulic stability," Nuclear Technology, 121 (1), pp. 52-62, 1998.

[32] A. Manera, "Experimental and analytical investigations on flashing-induced instabilities in natural circulation two-phase systems," (Dissertation), Delft University of Technology, 2003.

[33] S. Y. Jiang, M. S. Yao, J. H. Bo, and S. R. Wu, "Experimental simulation study on startup of the $5 \mathrm{MW}$ nuclear heating reactor," Nuclear Engineering and Design, 158 (1), pp. 111123, Sep. 1995.

[34] S. Shi, C.S. Brooks, J.H. Eoh, M. Ishii, "Pressurized Startup Transient Analyses for the BWR-type NMR-50," in ANS Winter Meeting and Nuclear Technology Expo, Anaheim, CA, 2014 
S. Shi, T. Hibiki, and M. Ishii/ Startup Instability in Natural Circulation Driven Nuclear Reactors

\title{
Startup Instability in Natural Circulation Driven Nuclear Reactors
}

\author{
Shanbin Shi ${ }^{\mathrm{a}}{ }^{*}$, Takashi Hibiki ${ }^{\mathrm{b}}$, Mamoru Ishii ${ }^{\mathrm{b}}$
}

\section{Captions of Figures}

Fig. 1. Density wave oscillations

Fig. 2. Stability plane [3]

Fig. 3. Furuya's SBWR stability map at $0.1,0.2,0.35$, and $0.5 \mathrm{MPa}[21]^{1}$

Fig. 4. Woo's SBWR stability map at 0.1, 0.2, 0.3, and 0.4 MPa [23]

Fig. 5. IMR stability map at $0.2 \mathrm{MPa}$ [24]

Fig. 6. NMR-50 stability map at $0.2 \mathrm{MPa}$ [27]

Fig. 7. Core inlet flow velocity profile at different phases [27]

Fig. 8. Power curve for the fast startup transients for the SBWR (55 ${ }^{\circ} \mathrm{C} /$ hour $)$ [23]

Fig. 9. Steam dome pressure for the fast startup transients for the SBWR [23]

Fig. 10. Core inlet velocity for the fast startup transients for the SBWR [23]

Fig. 11. Void fraction at the core exit for the fast startup transients for the SBWR [23]

Fig. 12. Power curve for the fast startup transients for the IMR [28]

Fig. 13. Steam dome pressure for the fast startup transients for the IMR [28]

Fig. 14. Core inlet velocity for the fast startup transients for the IMR [28]

Fig. 15. Power curve for the fast startup transients for the NMR-50 [6]

Fig. 16. Steam dome pressure for the fast startup transients for the NMR-50 [6]

Fig. 17. Natural circulation rate for the fast startup transients for the NMR-50 [6]

Fig. 18. Detailed void fraction at the core exit for the fast startup transients for the NMR-50 [6]

\footnotetext{
${ }^{1}$ Reprinted from IOS press, (ISBN print \#: 978-1-58603-605-8), M. Furuya, Experimental and analytical modeling of natural circulation and forced circulation BWRs: thermal-hydraulic, corewide, and regional stability phenomena, 2006, with permission from IOS press.
} 

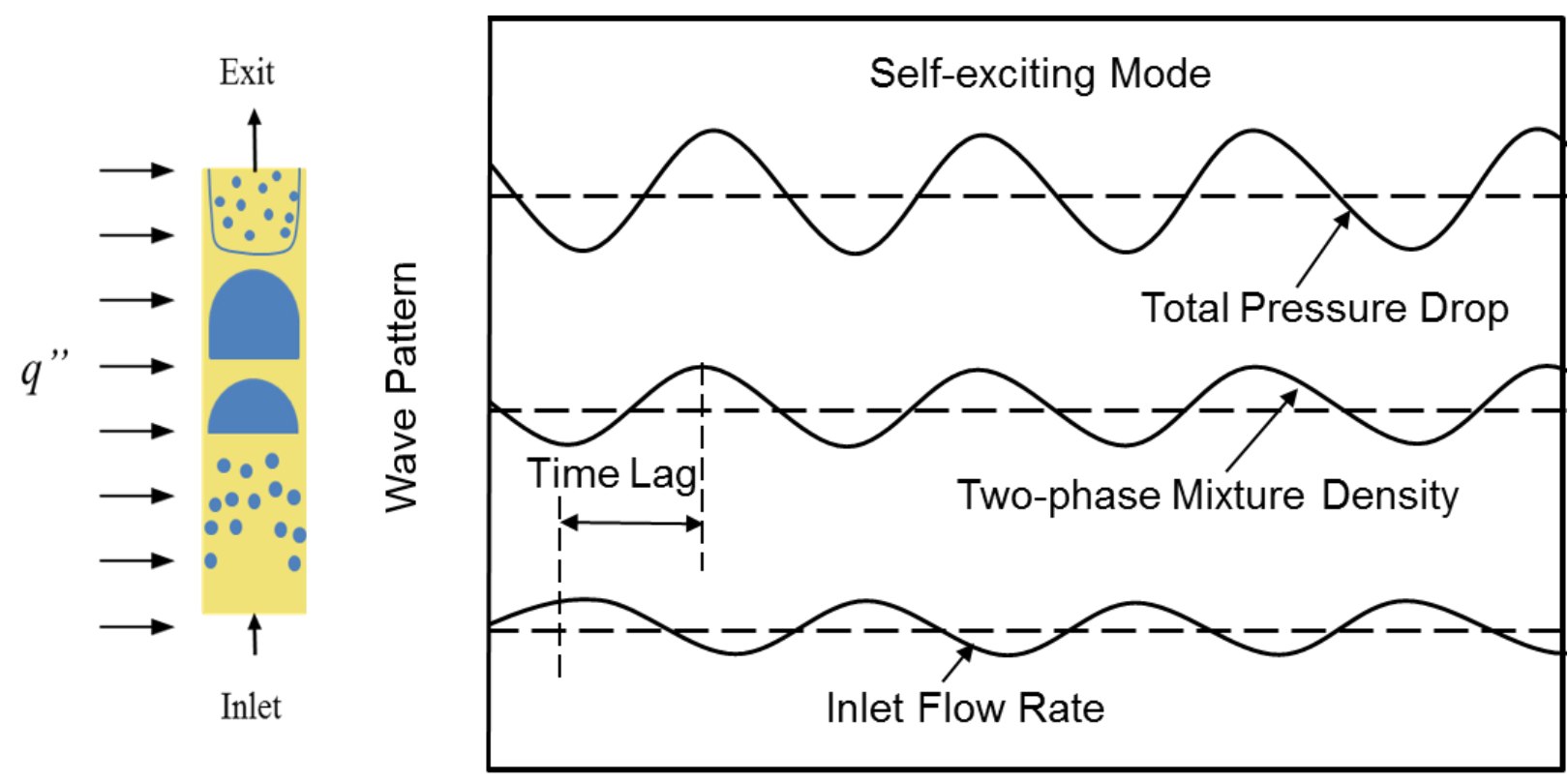

\section{Time}

S. Shi, T. Hibiki, and M. Ishii

Fig. 1 


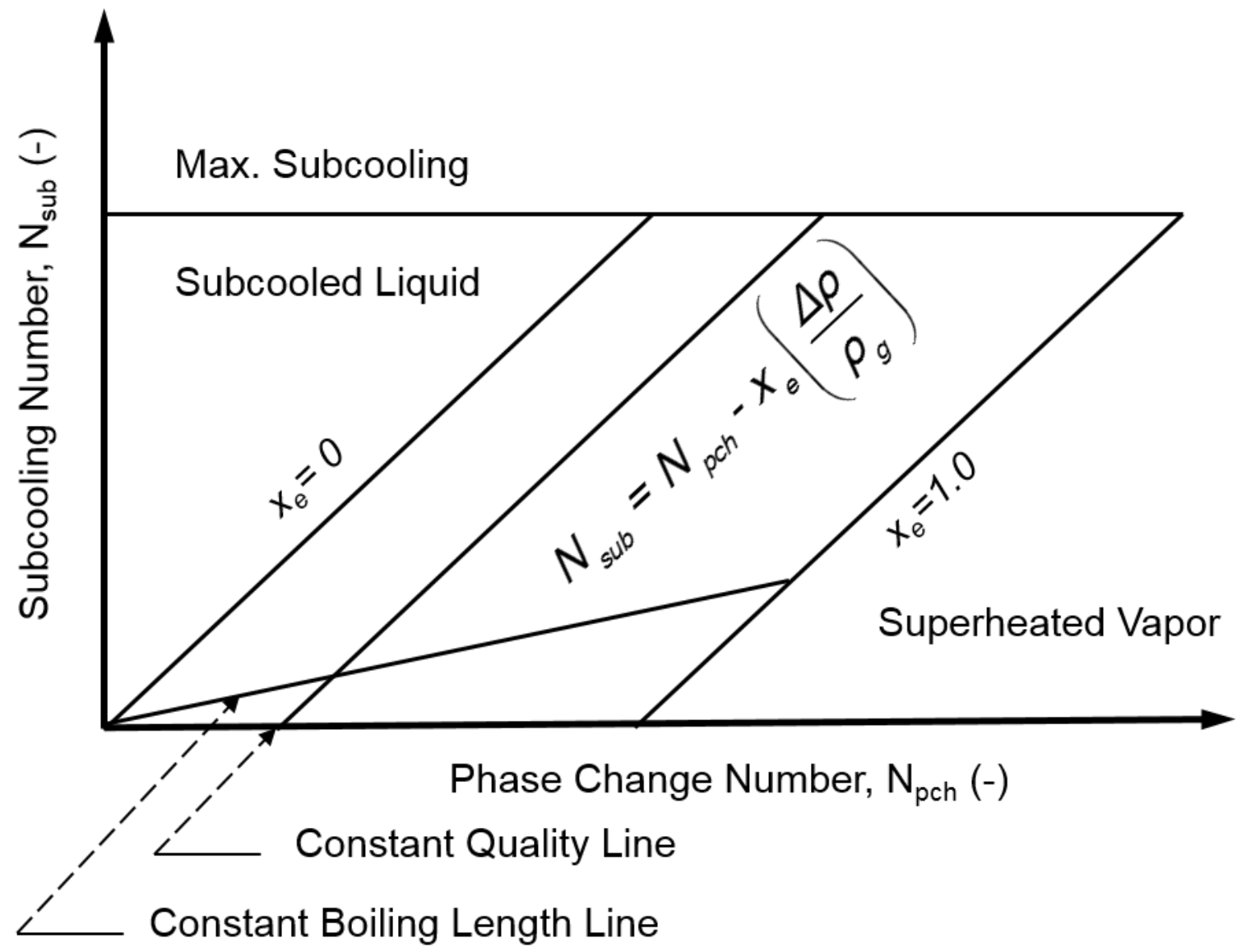

S. Shi, T. Hibiki, and M. Ishii

Fig. 2 
S. Shi, T. Hibiki, and M. Ishii/ Startup Instability in Natural Circulation Driven Nuclear Reactors

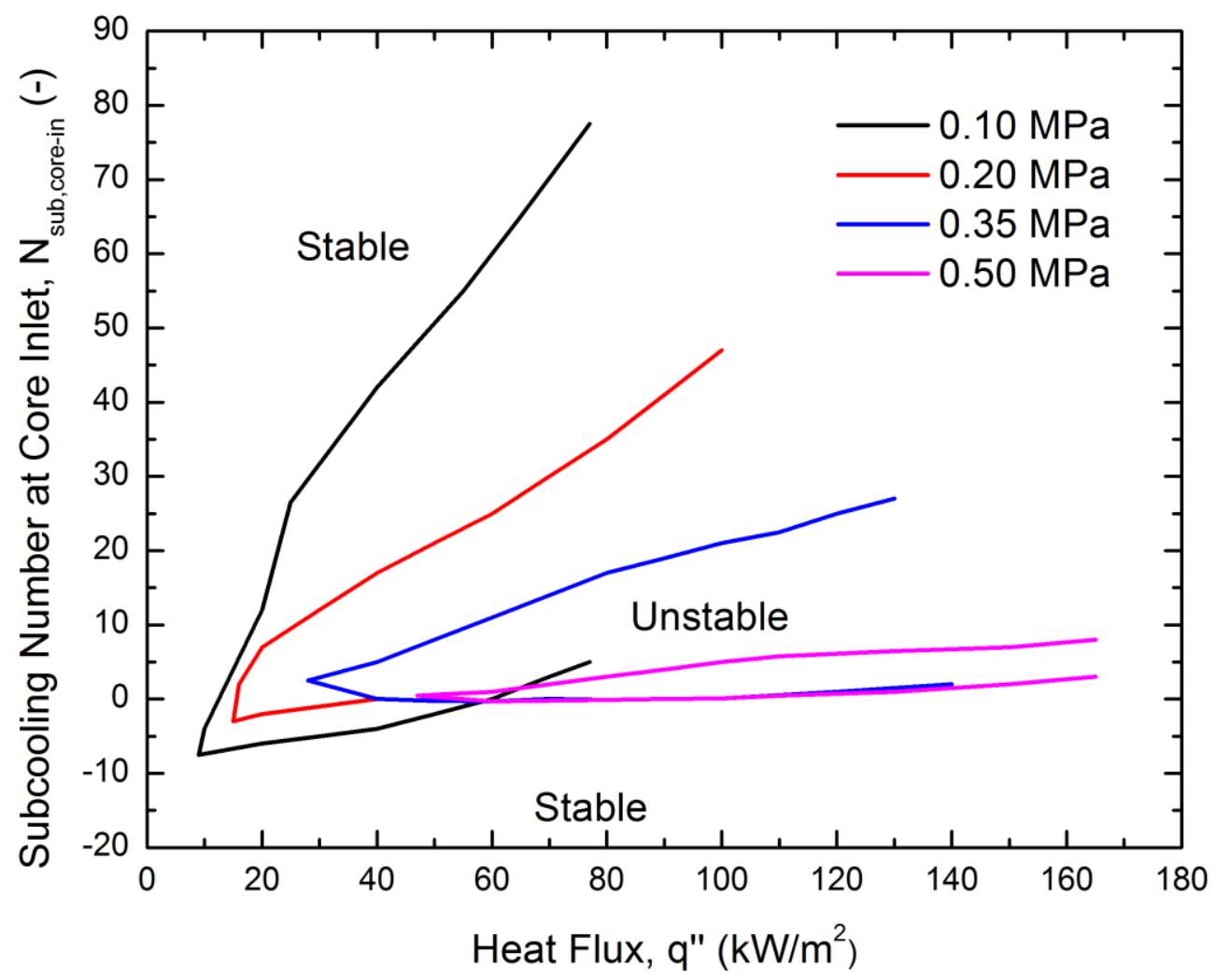

S. Shi, T. Hibiki, and M. Ishii

Fig. 3 
S. Shi, T. Hibiki, and M. Ishii/ Startup Instability in Natural Circulation Driven Nuclear Reactors

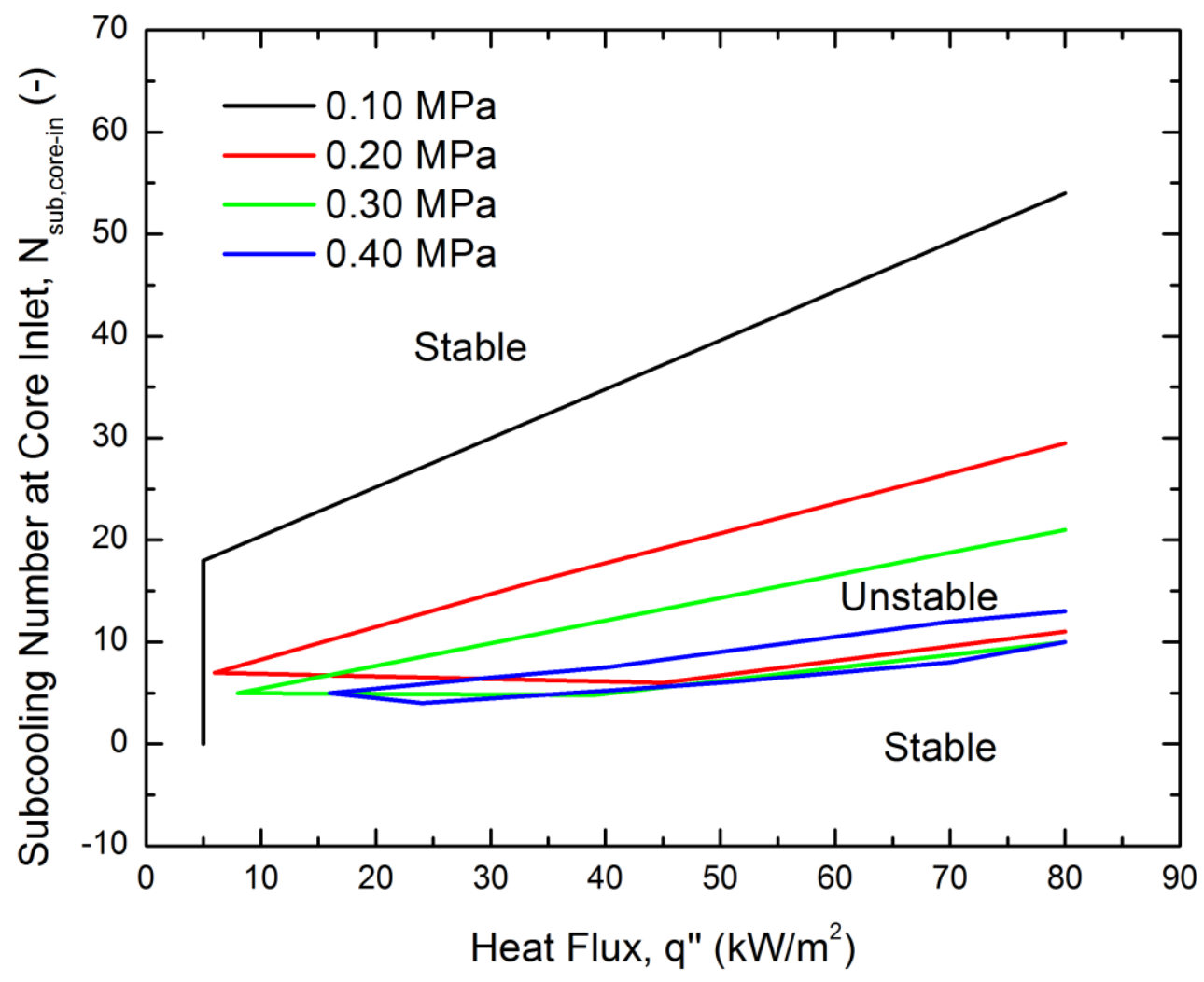

S. Shi, T. Hibiki, and M. Ishii

Fig. 4 
S. Shi, T. Hibiki, and M. Ishii/ Startup Instability in Natural Circulation Driven Nuclear Reactors

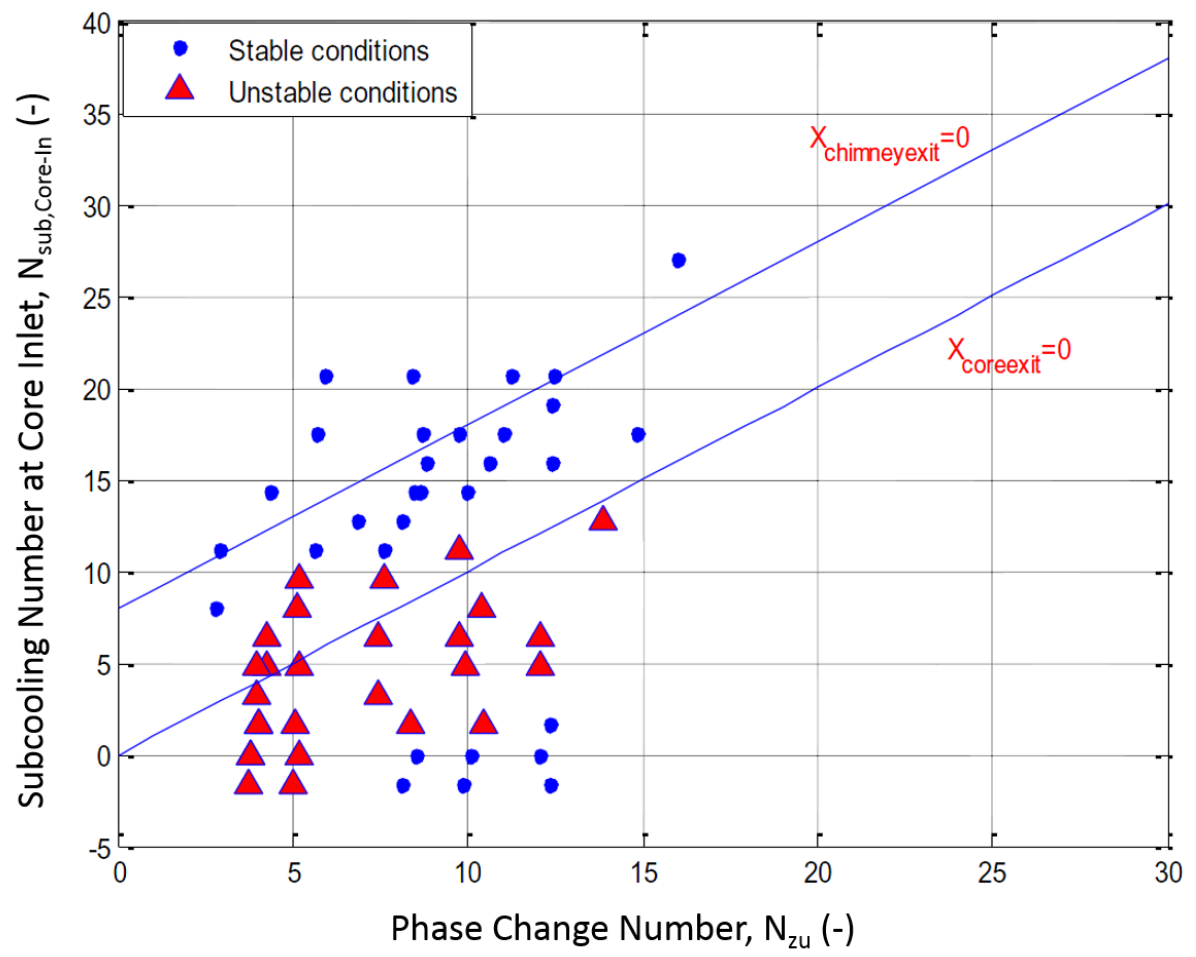

S. Shi, T. Hibiki, and M. Ishii Fig. 5 
S. Shi, T. Hibiki, and M. Ishii/ Startup Instability in Natural Circulation Driven Nuclear Reactors

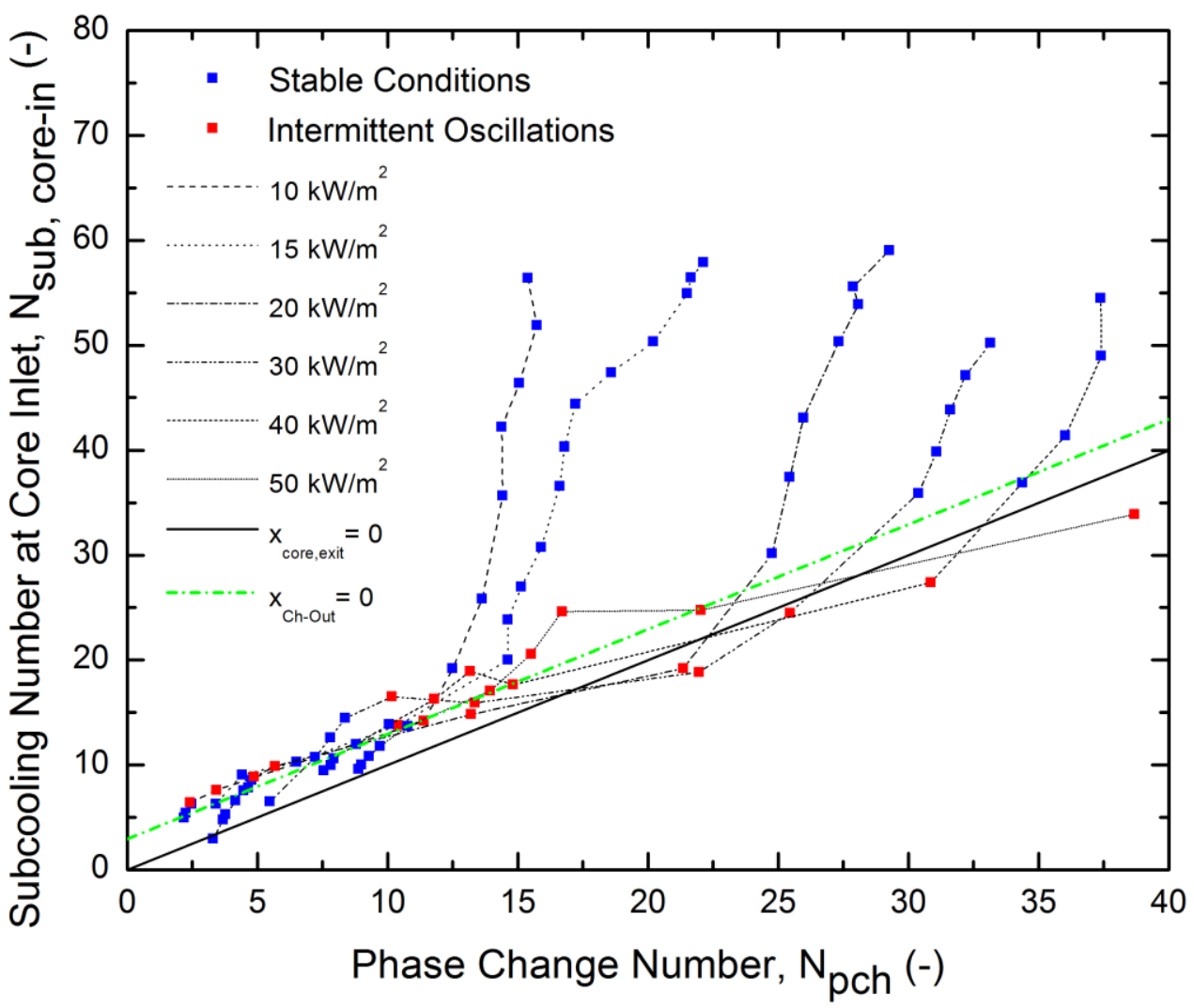

S. Shi, T. Hibiki, and M. Ishii

Fig. 6 
S. Shi, T. Hibiki, and M. Ishii/ Startup Instability in Natural Circulation Driven Nuclear Reactors

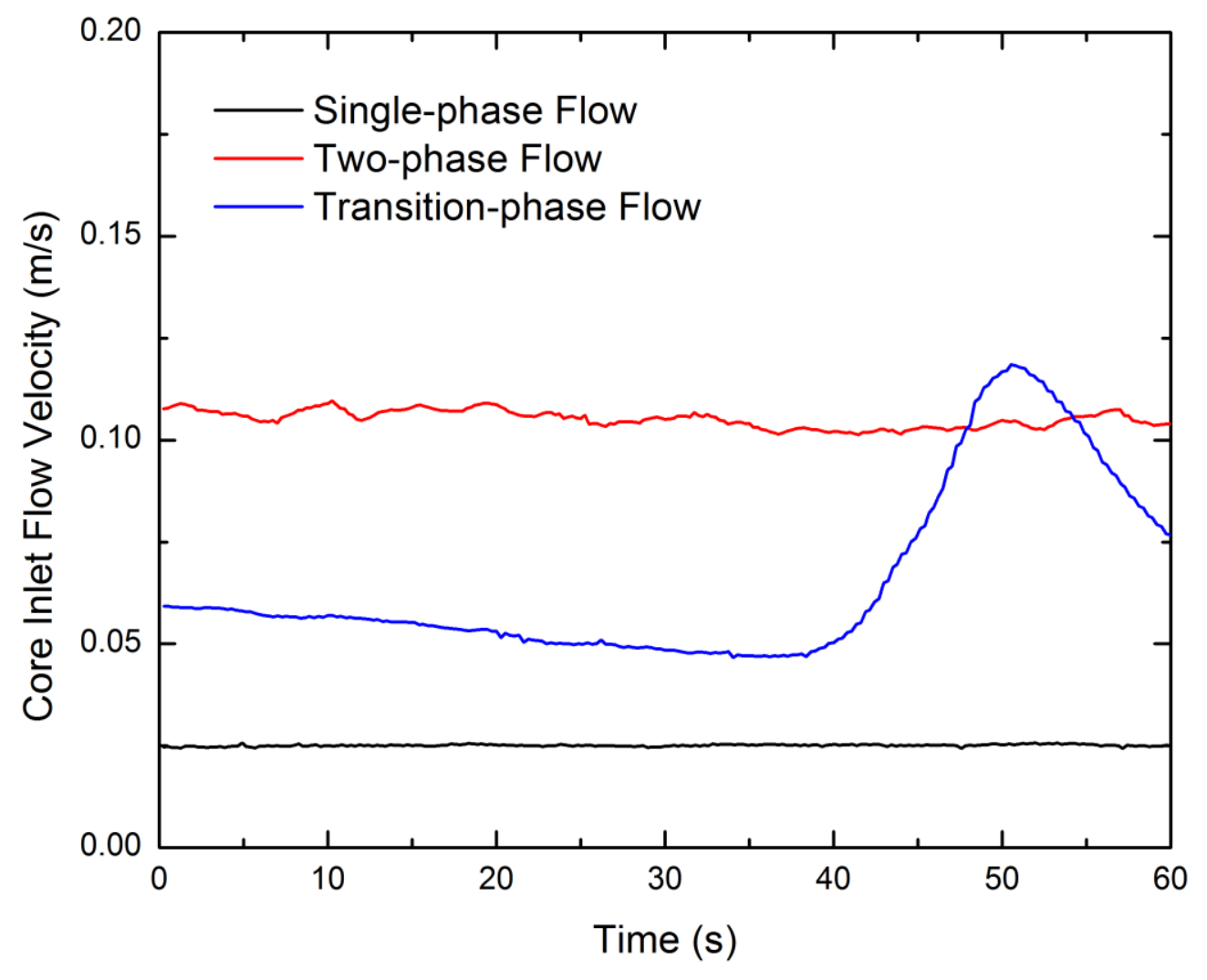

S. Shi, T. Hibiki, and M. Ishii

Fig. 7 
S. Shi, T. Hibiki, and M. Ishii/ Startup Instability in Natural Circulation Driven Nuclear Reactors

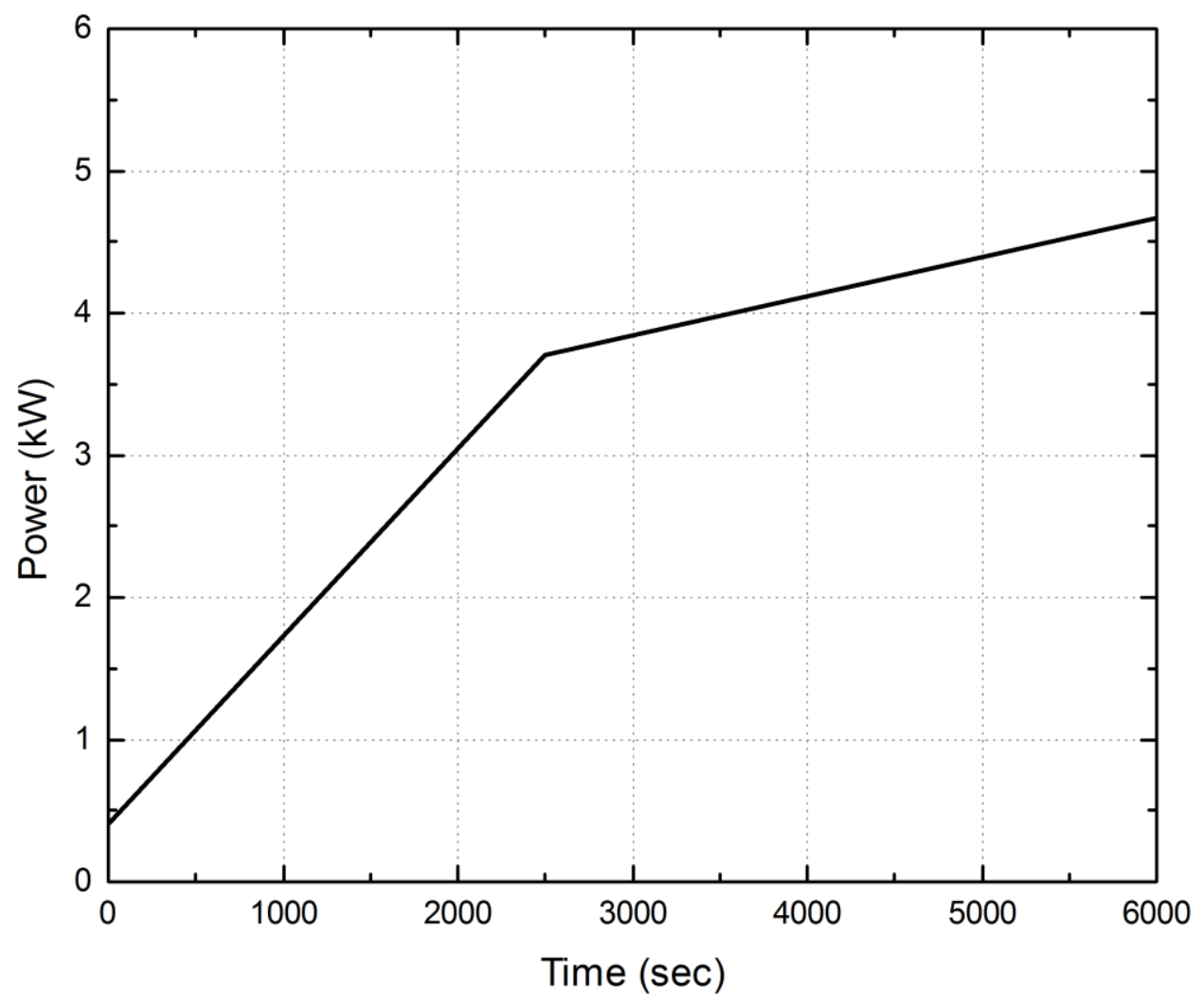

S. Shi, T. Hibiki, and M. Ishii

Fig. 8 
S. Shi, T. Hibiki, and M. Ishii/ Startup Instability in Natural Circulation Driven Nuclear Reactors

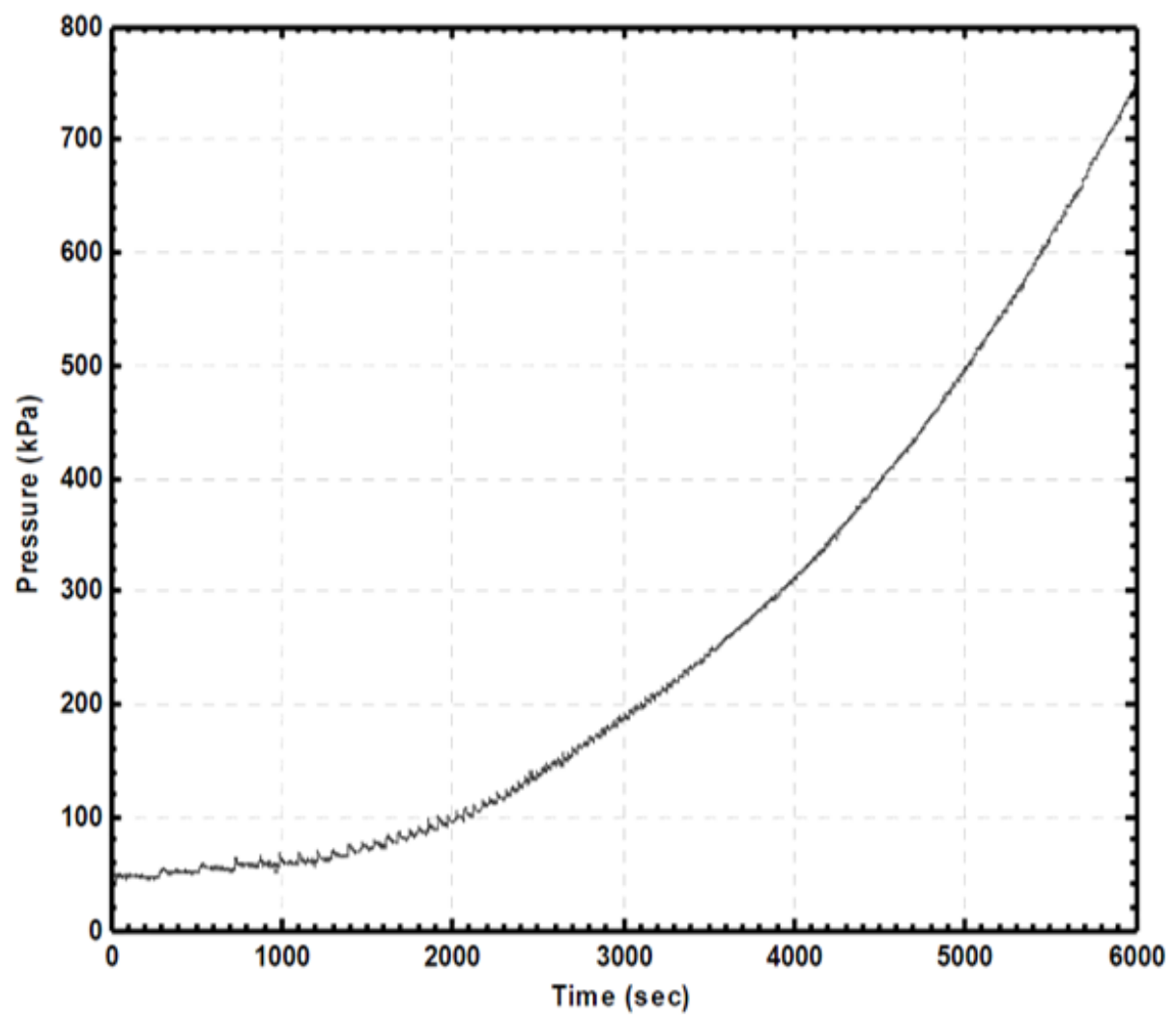

S. Shi, T. Hibiki, and M. Ishii

Fig. 9 
S. Shi, T. Hibiki, and M. Ishii/ Startup Instability in Natural Circulation Driven Nuclear Reactors
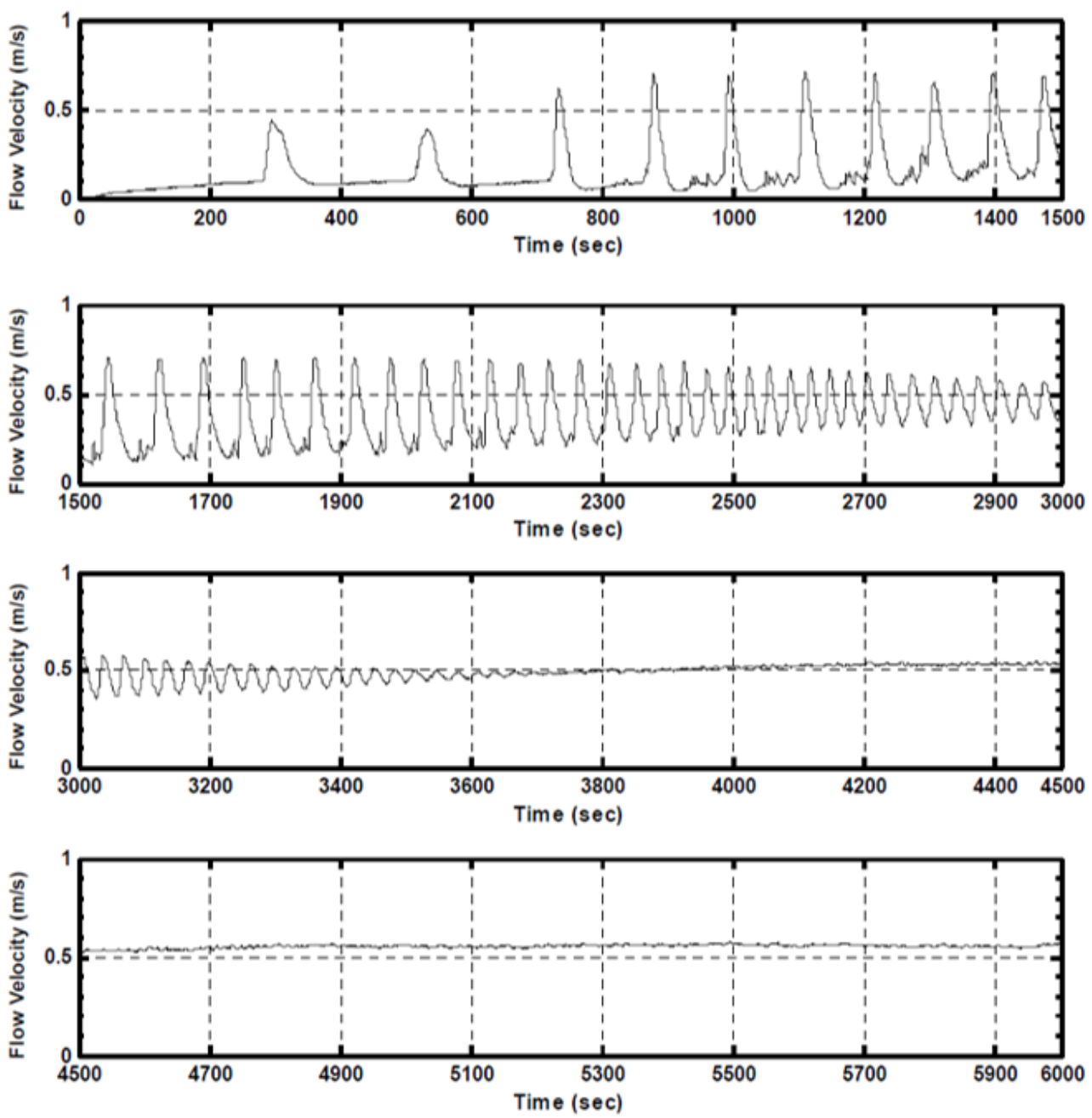

S. Shi, T. Hibiki, and M. Ishii

Fig. 10 
S. Shi, T. Hibiki, and M. Ishii/ Startup Instability in Natural Circulation Driven Nuclear Reactors
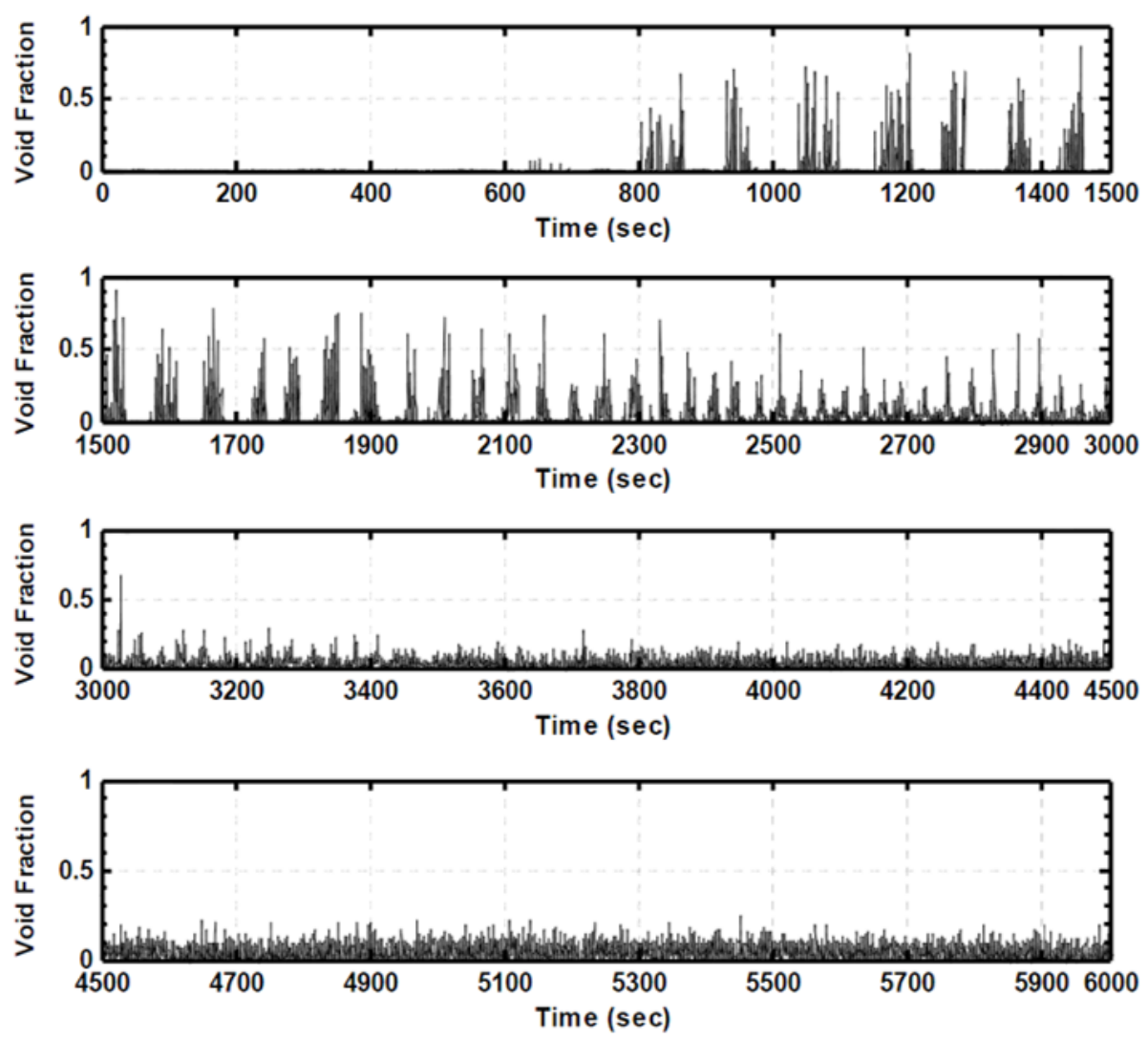

S. Shi, T. Hibiki, and M. Ishii Fig. 11 
S. Shi, T. Hibiki, and M. Ishii/ Startup Instability in Natural Circulation Driven Nuclear Reactors

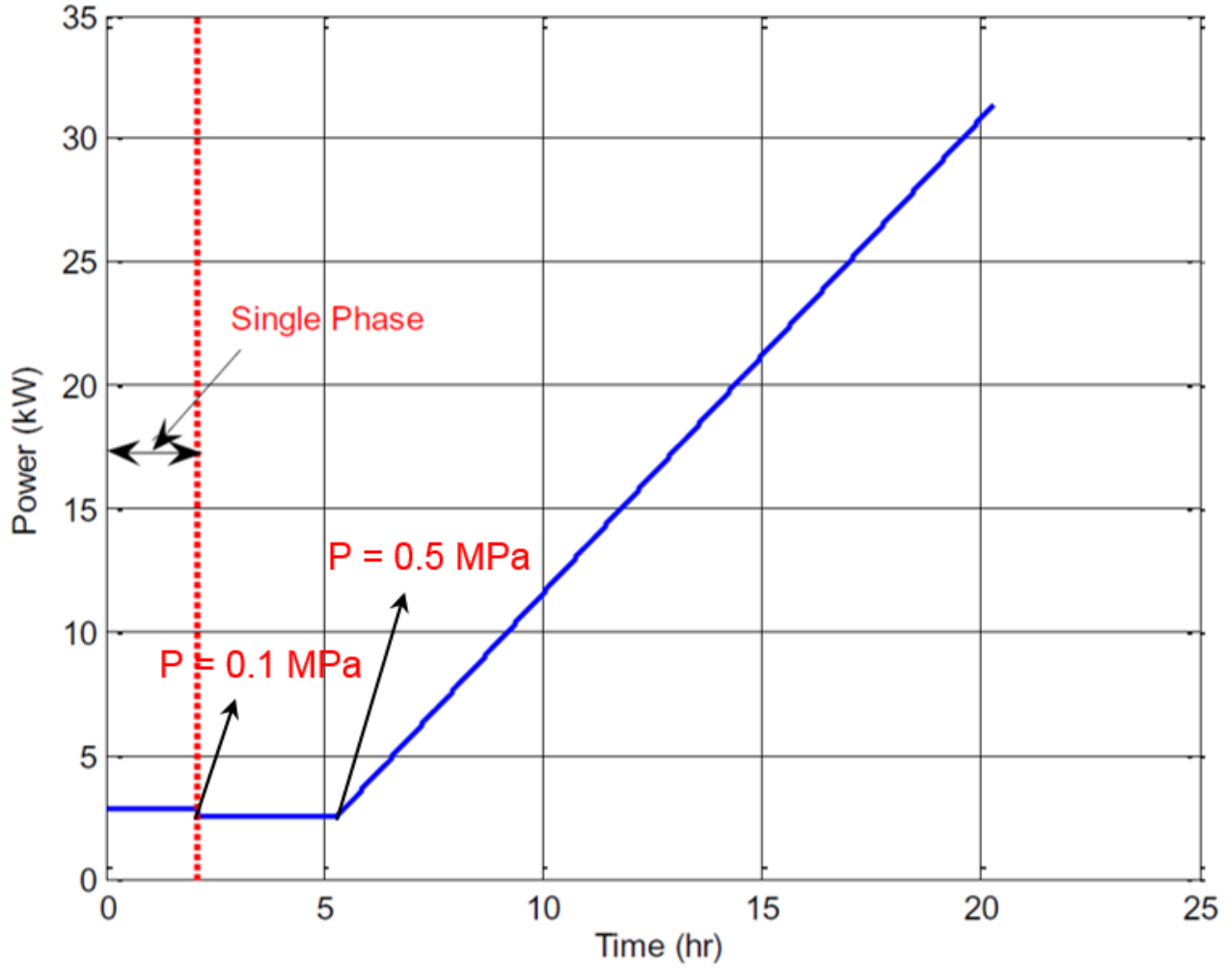

S. Shi, T. Hibiki, and M. Ishii

Fig. 12 
S. Shi, T. Hibiki, and M. Ishii/ Startup Instability in Natural Circulation Driven Nuclear Reactors

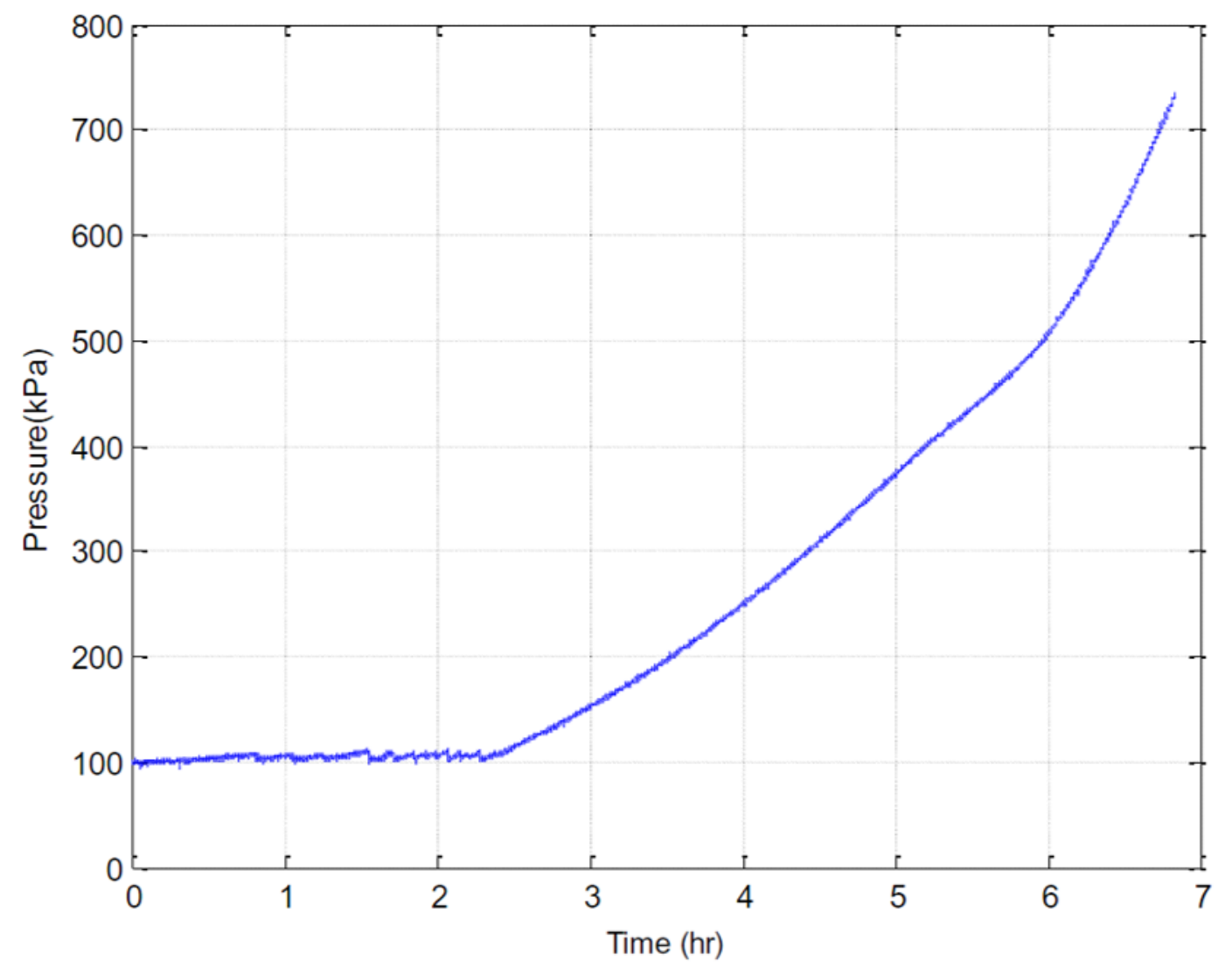

S. Shi, T. Hibiki, and M. Ishii

Fig. 13 

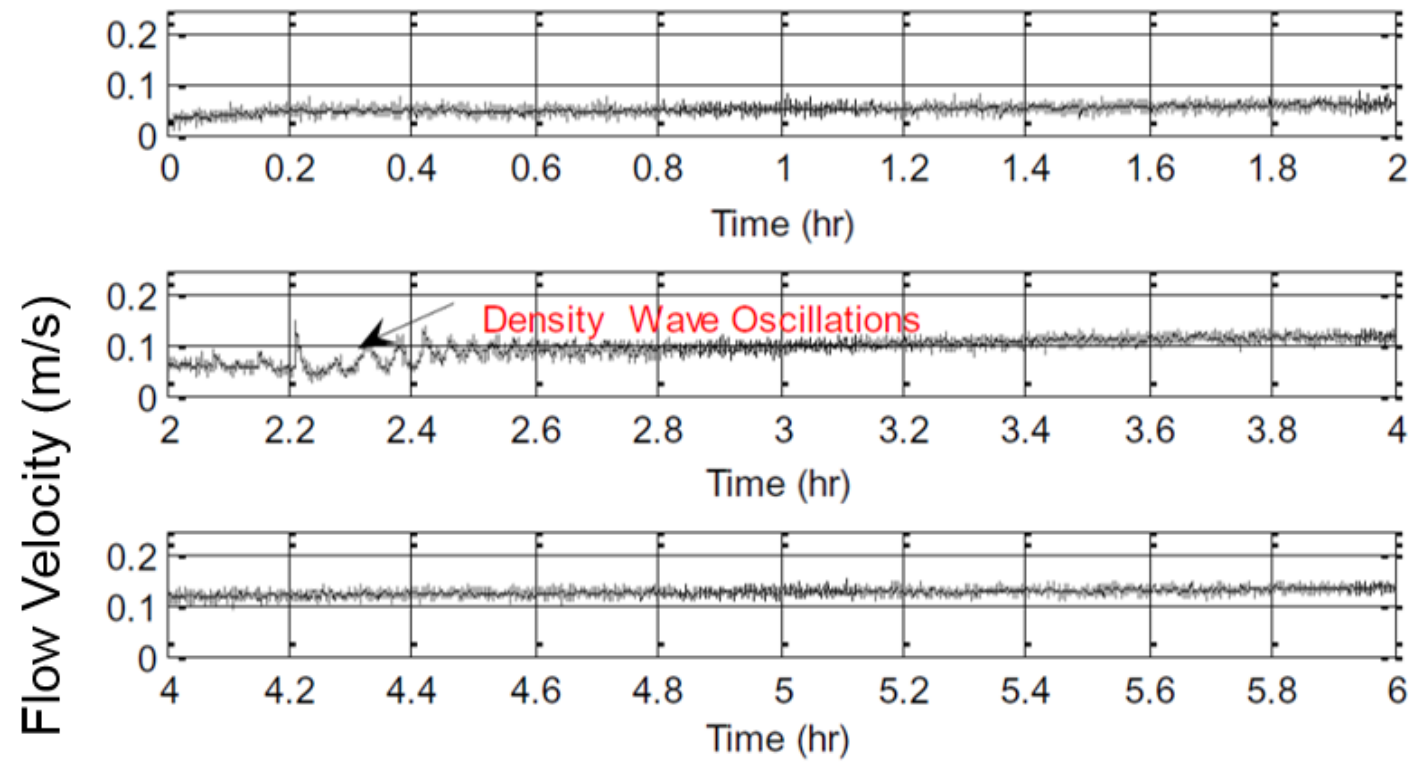

Flow velocity at core inlet

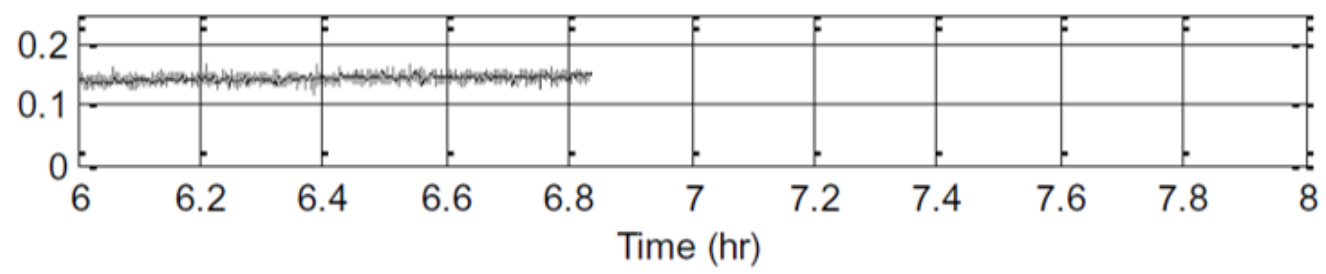

S. Shi, T. Hibiki, and M. Ishii

Fig. 14 
S. Shi, T. Hibiki, and M. Ishii/ Startup Instability in Natural Circulation Driven Nuclear Reactors

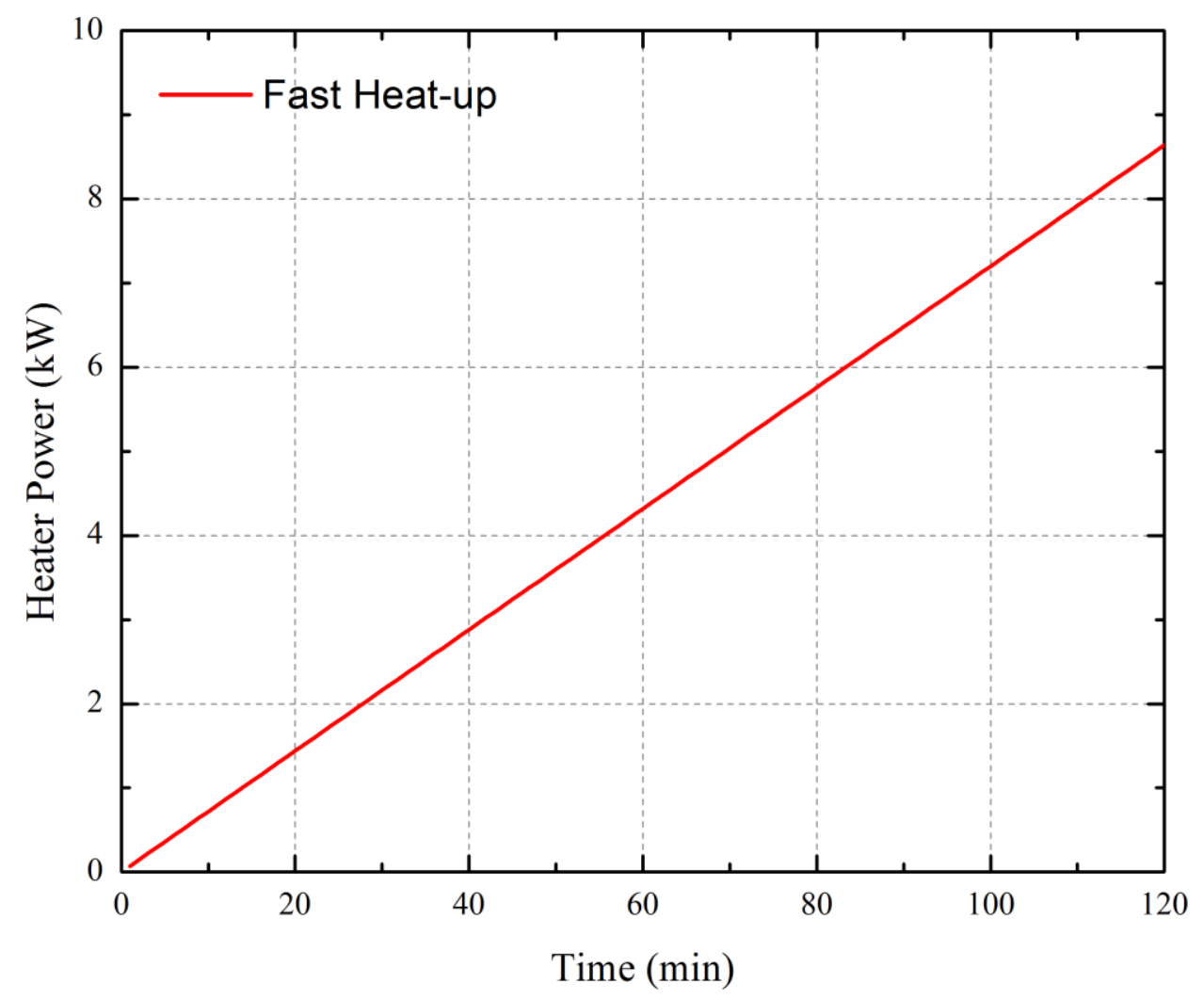

S. Shi, T. Hibiki, and M. Ishii

Fig. 15 
S. Shi, T. Hibiki, and M. Ishii/ Startup Instability in Natural Circulation Driven Nuclear Reactors

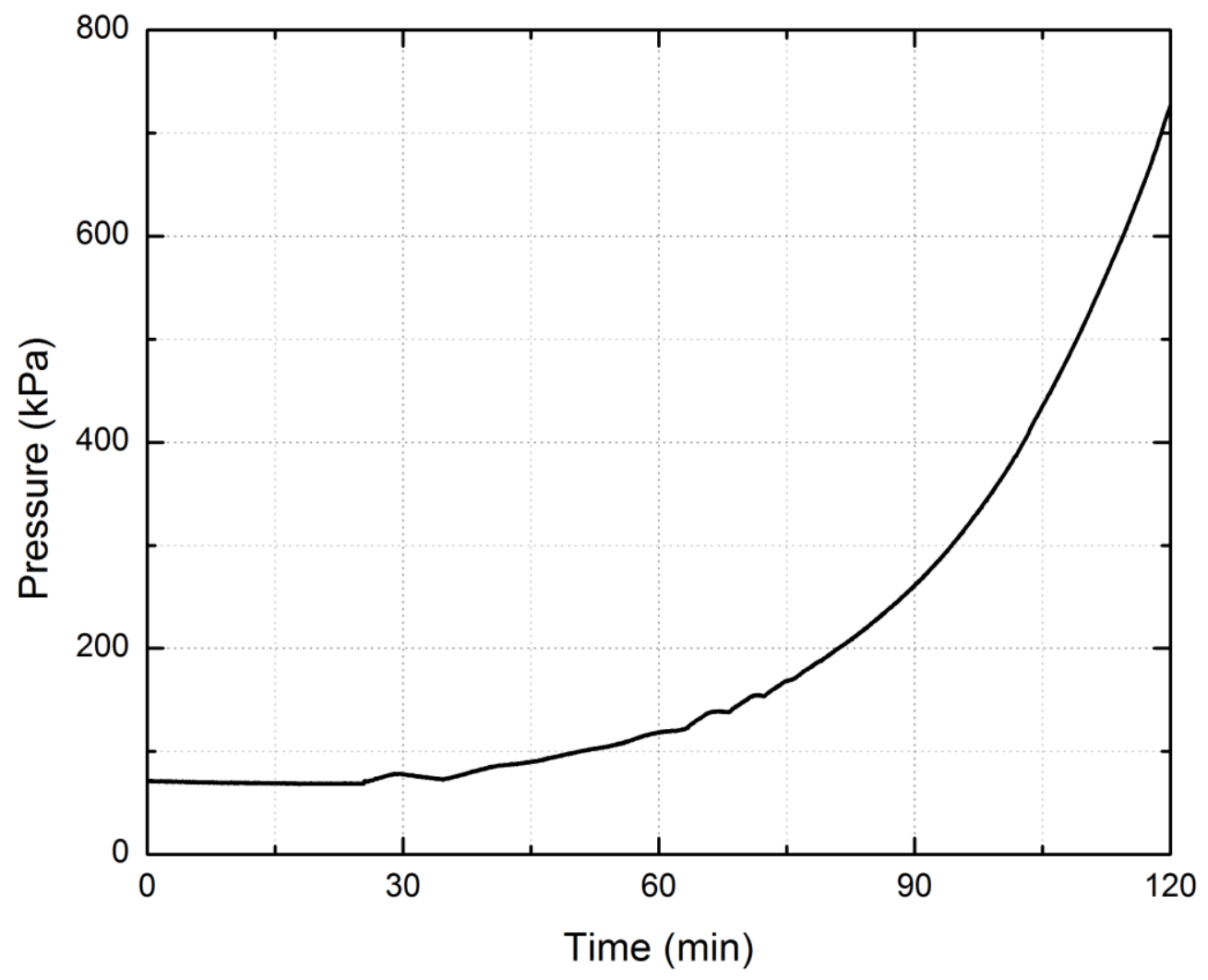

S. Shi, T. Hibiki, and M. Ishii

Fig. 16 
S. Shi, T. Hibiki, and M. Ishii/ Startup Instability in Natural Circulation Driven Nuclear Reactors

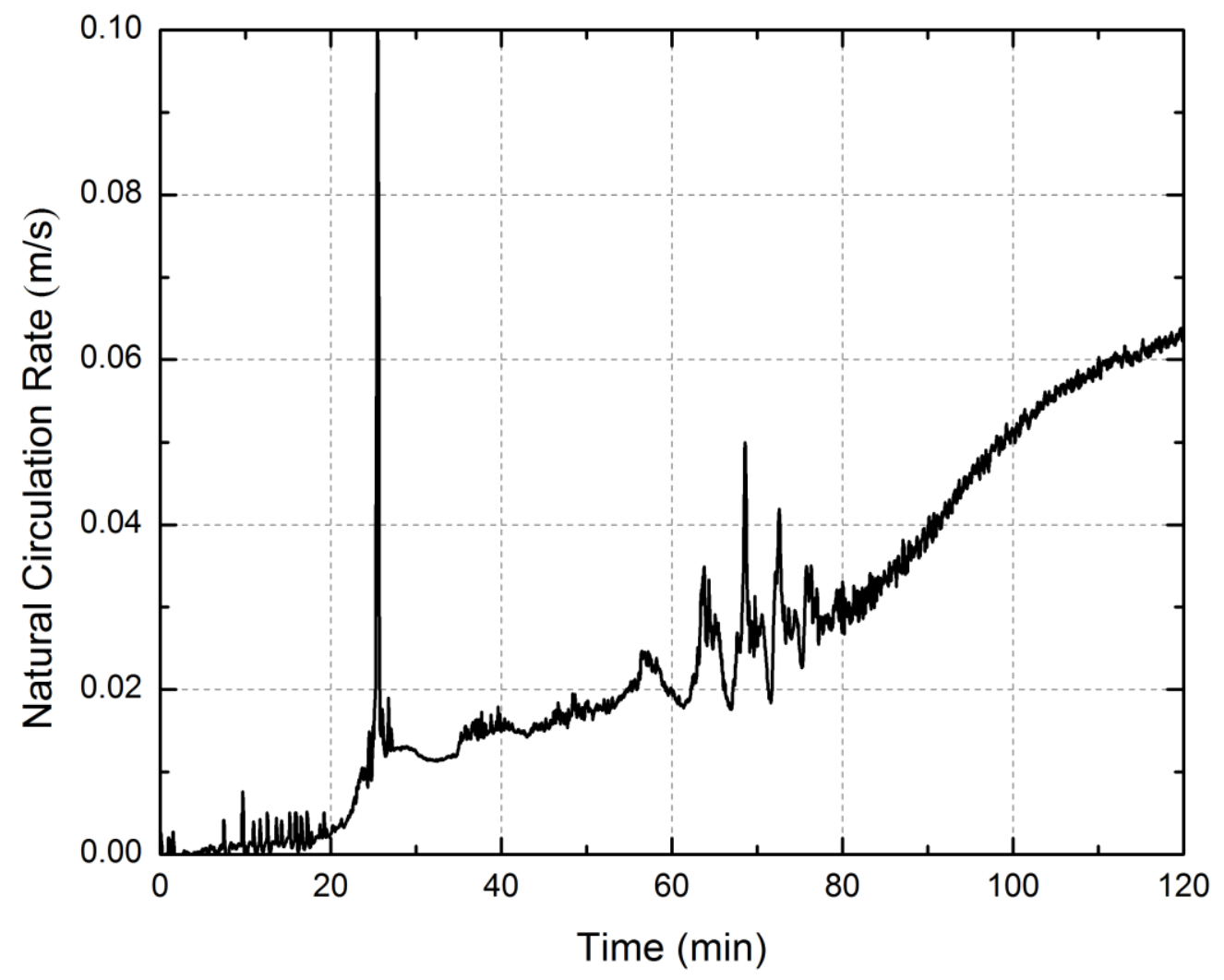

S. Shi, T. Hibiki, and M. Ishii

Fig. 17 
S. Shi, T. Hibiki, and M. Ishii/ Startup Instability in Natural Circulation Driven Nuclear Reactors

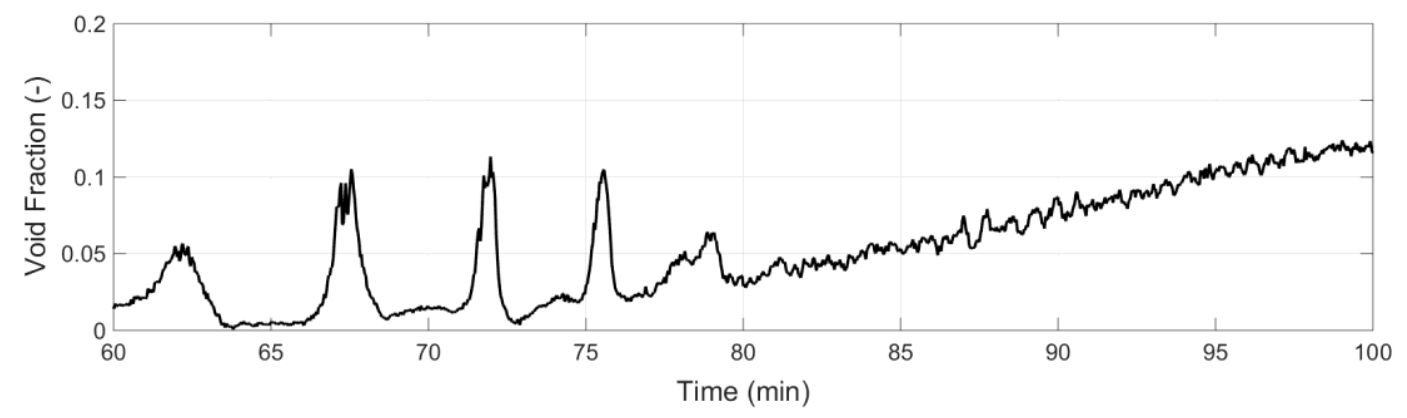

S. Shi, T. Hibiki, and M. Ishii

Fig. 18 